\title{
A novel approach to sulfate geoengineering with surface emissions of carbonyl sulfide
}

\author{
Ilaria Quaglia ${ }^{1}$, Daniele Visioni ${ }^{2}$, Giovanni Pitari ${ }^{1}$, and Ben Kravitz ${ }^{3,4}$ \\ ${ }^{1}$ Department of Physical and Chemical Sciences, Universitá dell'Aquila, 67100 L'Aquila, Italy \\ ${ }^{2}$ Sibley School for Mechanical and Aerospace Engineering, Cornell University, Ithaca, NY 14853, USA \\ ${ }^{3}$ Department of Earth and Atmospheric Science, Indiana University, Bloomington, IN, USA \\ ${ }^{4}$ Atmospheric Sciences and Global Change Division, Pacific Northwest National Laboratory, Richland, WA, USA
}

Correspondence: Ilaria Quaglia (ilaria.quaglia@aquila.infn.it)

\begin{abstract}
Sulfate geoengineering (SG) methods based on lower stratospheric tropical injection of sulfur dioxide $\left(\mathrm{SO}_{2}\right)$ have been widely discussed in recent years, focusing on the direct and indirect effects they would have on the climate system. Here a potential alternative method is discussed, where sulfur emissions are located at the surface in the form of carbonyl sulfide (COS) gas. A time-dependent chemistry-climate model experiment is designed from year 2021 to 2055 , assuming a $40 \mathrm{Tg}-\mathrm{S} / \mathrm{yr}$ artificial global flux of COS, geographically distributed following the present day anthropogenic COS surface emissions. The budget of COS and sulfur species is discussed, as well as the effects of SG-COS on the stratospheric sulfate aerosol optical depth $(\Delta \tau=0.080$ in years $2046-2055)$, aerosol effective radius $(0.46 \mu \mathrm{m})$, surface $\mathrm{SO}_{x}$ deposition $(+8.7 \%)$ and tropopause radiative forcing $(\mathrm{RF})\left(-2.0 \mathrm{~W} / \mathrm{m}^{2}\right.$ for clear sky conditions and $-1.5 \mathrm{~W} / \mathrm{m}^{2}$ including the cloud adjustment). Indirect effects on ozone, methane and stratospheric water vapor are also considered, along with the COS direct contribution (with an overall gas phase global radiative forcing of $+0.23 \mathrm{~W} / \mathrm{m}^{2}$ ). According to our model results, the resulting net RF of this SG-COS experiment is $-1.3 \mathrm{~W} / \mathrm{m}^{2}$ for the year 2050 , and it is comparable to the corresponding RF of $-1.7 \mathrm{~W} / \mathrm{m}^{2}$ obtained with a sustained injection of $4 \mathrm{Tg}-\mathrm{S} / \mathrm{yr}$ in the tropical lower stratosphere in the form of $\mathrm{SO}_{2}$ (SG-SO2, able to produce a comparable increase of the sulfate aerosol optical depth). Significant changes of the stratospheric ozone response are found in SG-COS with respect to SG-SO2 (+4.9 DU versus +1.5 DU, globally). According to the model results, the resulting UVB perturbation at the surface accounts to $-4.3 \%$ as a global-annual average (versus $-2.4 \%$ in the SG-SO2 case), with a springtime Antarctic decrease of $-2.7 \%$ (versus $\mathrm{a}+5.8 \%$ increase in the SG-SO2 experiment). Overall, we find that an increase in COS surface emission may be feasible, and produce a more latitudinally-uniform forcing without the need for the deployment of stratospheric aircrafts.
\end{abstract}

\section{Introduction}

Reducing part of the incoming solar radiation (known as Solar Radiation Modification, SRM) has been proposed as a short-term strategy for reducing surface temperatures and thus mitigating some of the worst side-effects of the greenhouse gases-induced global warming (Budyko, 1978; Crutzen, 2006). Various methods have been proposed to achieve this: the injection of sulfate precursors into the lower stratosphere to obtain an optically-active cloud of aerosols has been, by far, the most studied due to the observation of a similar cooling effect produced by explosive volcanic eruptions in the past (Robock, 2000). While preliminary 
estimates for the cost of an eventual deployment already exist (Smith and Wagner, 2018), from an engineering perspective there are no known technologies readily available to carry $\mathrm{SO}_{2}$ or any other precursors considered up to now from the ground up to the lower stratosphere in the quantities needed to obtain a noticeable effect on the surface climate (Lockley et al., 2020). Since any proposed compound would quickly react to form sulfate aerosols, they would need to be carried sealed to the desired altitude, and then released, to ensure a high enough lifetime compared to that of the same aerosols in the troposphere (Lamarque et al., 2013).

We propose here a different approach to increasing the aerosol optical depth in the stratosphere, that makes use of bottom-up emissions of a gaseous precursor of sulfate aerosols: carbonyl sulfide (COS). COS has a long atmospheric lifetime (4 to 6 years; Khalil and Rasmussen, 1984; Ulshofer et al., 1996) due to its very low reactivity in the troposphere. Because of this, it is also uniformly mixed in the atmosphere, with an average concentration of 0.5 ppbv, and therefore it easily reaches the stratosphere: in quiescent volcanic conditions, COS is the main contributor of sulfate aerosols in the Junge layer (Bruhl et al., 2012), where after photodissociation by ultraviolet light and oxidation processes, it is turned into $\mathrm{SO}_{2}$ and subsequently oxidized into sulfuric acid, forming sulfate aerosols (Crutzen, 1976). It is naturally produced by various biological processes and environments, such as saline ecosystems, rainwaters (Mu et al., 2004) and biomass burning. Furthermore, it is also produced in various industrial processes (Lee and Brimblecombe, 2016) after $\mathrm{CS}_{2}$ is oxidized. Its chemical life is very long (35 years; Bruhl et al., 2012) and thus its main sink is the uptake from oxic soils (Kuhn and Kesselmeier, 2000; Steinbacher et al., 2004) and vegetation (Sandoval-Soto et al., 2005). In the concentrations found in the atmosphere, it is not a toxic gas for humans or ecosystems: negative effects have been found only when concentration exceed 50 ppm $(100,000$ times more than the background mixing ratio (Kilburn and Warshaw, 1995; Bartholomaeus and Haritos, 2006).

For these reasons, we investigate in this work the possible use of COS as a precursor to stratospheric sulfate aerosols aimed at reducing part of the incoming solar radiation. With the use of the University of L'Aquila-Climate-Chemistry Model (ULAQ-CCM) we investigate the possible increase of COS surface fluxes to obtain a stratospheric aerosol optical depth (AOD) similar to that obtained with the injection of $8 \mathrm{Tg}-\mathrm{SO}_{2}$ in the stratosphere. Together with assessing the resulting optically thick aerosol cloud, we also explore the eventual side-effects on key chemical components in the atmosphere, in order to determine how the side effects from COS-induced Sulfate Geoengineering (SG-COS) compare with those from $\mathrm{SO}_{2}$-induced Sulfate Geoengineering (SG-SO2). For the latter, there is ample literature assessing its effect on stratospheric ozone (Tilmes et al., 2008; Pitari et al., 2014; Xia et al., 2017a; Vattioni et al., 2019): the increase in surface area density, stratospheric heating and dynamical effect all play a part in determining the overall changes (Tilmes et al., 2018b; Richter et al., 2017) to the ozone column that, in turn, determine the changes in surface UV (Visioni et al., 2017b; Madronich et al., 2018) that would be important when considering adverse health effects (Eastham et al., 2018).

\section{Model description and setup of numerical experiments}

The simulations presented in this paper have been carried out with the University of L'Aquila Climate-Chemistry Model (ULAQ-CCM), a CCM robustly tested and used before in evaluation of the radiative, chemical and dynamical effects of 
stratospheric and tropospheric aerosols (Pitari et al., 2002; Eyring et al., 2006; Morgenstern et al., 2010). It has also been used for various sulfate geoengineering simulations (Pitari et al., 2014; Visioni et al., 2018a, b) and, as part of the ClimateChemistry Model Intercomparison project (Morgenstern et al., 2018), where it has been extensively validated with other CCMs.

The high vertical resolution (127 levels) allows for a proper representation of large-scale transport of gas and aerosol species in the troposphere (Orbe et al., 2018) and in the stratosphere (Visioni et al., 2017b; Eichinger et al., 2019), and the detailed chemistry, including heterogeneous chemical reactions on sulfuric acid aerosols, polar stratospheric cloud particles, upper tropospheric ice and liquid water cloud particles allows for a full assessment of the effects of the increased sulfate burden on the atmospheric composition. ULAQ-CCM simulated COS also compares reasonably well with available measurements of seasonal COS concentrations (see Fig. S1) from Kuai et al. (2015), with an average annual error of 6.5\%, albeit with peaks in some areas and months of up to $30 \%$.

In addition to a reference historical model experiment (1960-2015), we performed three sets of simulations: a baseline unperturbed (BG) case and two geoengineering experiments (SG-COS and SG-SO2), all run between the years 2021-2055, with analyses focusing on the 2046-2055 decade; all experiments take place under the Representative Concentration Pathway 6.0 (RCP; Meinshausen et al., 2011) emissions.

The first geoengineering experiment, SG-COS, tries to produce a significant stratospheric aerosol burden by enhancing current surface emission sources of COS by up to $40 \mathrm{Tg}-\mathrm{S} / \mathrm{yr}$. These emissions are located at the ground, in the main regions of anthropogenic COS surface emissions (see Fig. 1). The second experiment, SG-SO2, is very similar to previous experiments discussed in the literature, primarily by Kravitz et al. (2011) in the G4 experiment, and consist of the injection of a fixed yearly amount of $\mathrm{SO}_{2}(4 \mathrm{Tg}-\mathrm{S} / \mathrm{yr})$ at the equator, between 18 and $25 \mathrm{~km}$ of altitude.

For the geoengineering experiments, ULAQ-CCM is driven by time-dependent sea surface temperatures (SSTs) from the Community Climate System Model - Community Atmosphere Model version 4 (CCSM-CAM4; Neale et al., 2013), an atmosphere-ocean coupled model that ran similar geoengineering experiments as in SG-SO2 (described by Tilmes et al., 2015): this allows for the inclusion of the cooling produced by geoengineering on the surface to the assessment of the dynamical and chemical effect as simulated by ULAQ-CCM. To include the important radiative effects produced by other atmospheric components (mainly, geoengineering-driven changes in greenhouse gases concentration and in ice clouds ; Visioni et al., 2017b, 2018a) the radiative module of ULAQ-CCM calculates at each time-step the surface temperature perturbation produced by the radiative flux changes induced by these components and includes them in the CCSM-CAM4 SSTs. This approach has been further explained and validated by Visioni et al. (2018a). While the prescribed SST setup has been shown to correctly capture dynamical changes produced by SRM (Visioni et al., 2017b), it clearly does not capture potential feedbacks that may be relevant for surface climate, such as those produced by the different latitudinal distribution of the aerosol optical depth that we will show later on. These differences may also in turn feed back onto changes in COS lifetime through precipitation changes (Whelan et al., 2016) which we can't consider here. We will therefore limit ourselves to analyzing changes in atmospheric composition and dynamics, and how those contribute to the overall radiative forcing from the aerosols. Future experiments with a more comprehensive Earth-system model will be necessary to determine the full extent of the climatic response. 


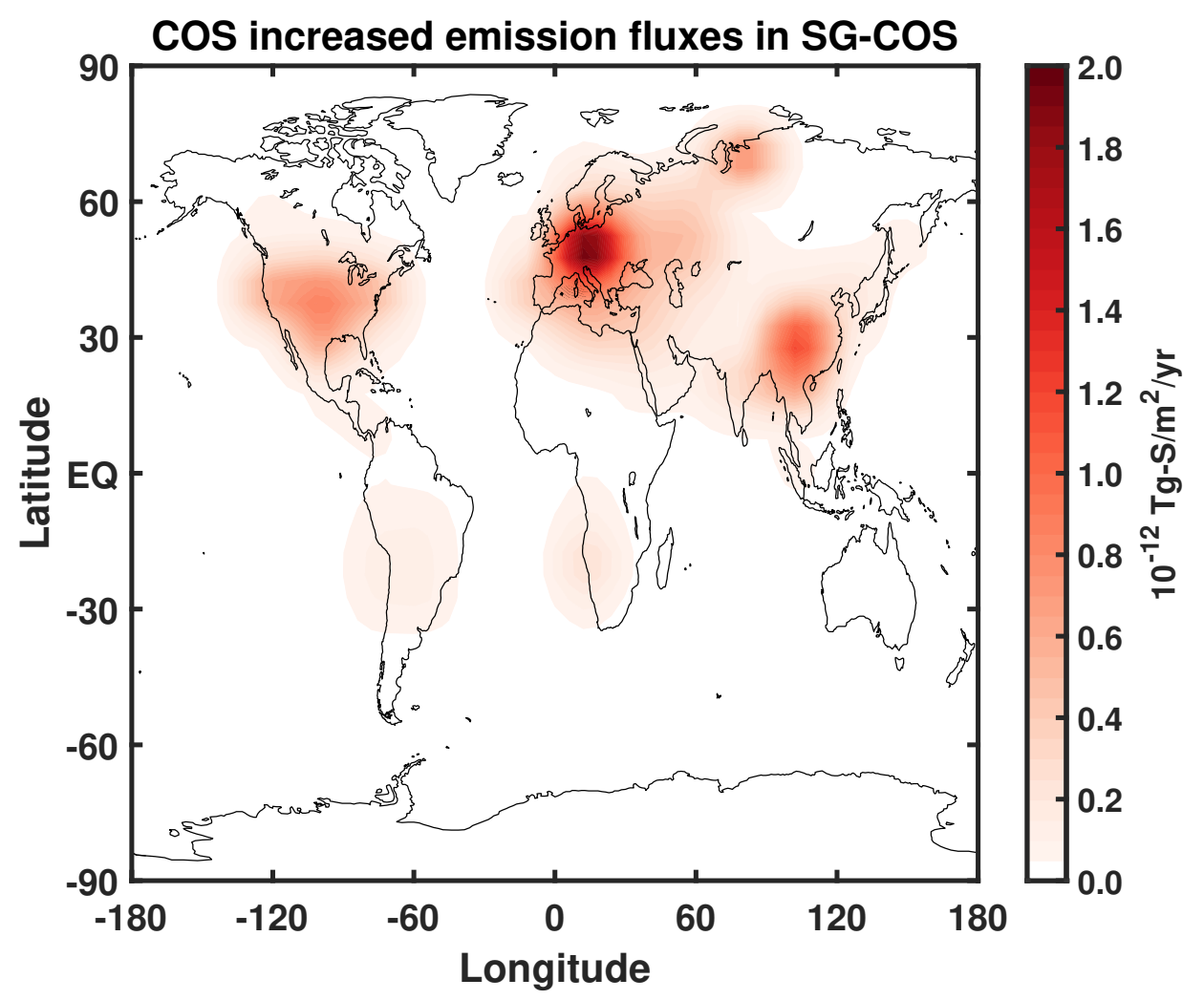

Figure 1. Geographical distribution of COS emission fluxes per year and unit of surface area $\left(10^{-12} \mathrm{Tg}-\mathrm{S} / \mathrm{m}^{2} / \mathrm{yr}\right)$ in the SG-COS experiment. The annual upward flux is averaged over the period 2046-2055.

\section{Results}

\subsection{Sulfate burden}

$\mathrm{COS}$ is the most abundant sulfur-containing species in the atmosphere under quiescent conditions (i.e. not considering explosive volcanic eruptions). It is efficiently lost at the surface via dry deposition on soils and vegetation: taking this sink into account, the net global lifetime (atmospheric chemistry plus surface deposition) is approximately 4 years, depending on the assumed magnitude of the soil and vegetation sink (Sandoval-Soto et al., 2005; Van Diest and Kesselmeier, 2008). In the troposphere the COS chemical reactivity (mostly with the hydroxyl radical) is rather slow: COS is thus well mixed and is easily transported in the stratosphere through the tropical tropopause layer (TTL). In the mid-stratosphere COS becomes efficiently photolyzed by solar UV radiation, becoming an important source for stratospheric $\mathrm{SO}_{2}$ and finally for sulphuric acid aerosols.

When increasing the emission fluxes in SG-COS, it takes $\sim 15$ years before the concentration reaches a new equilibrium, from 0.5 to $35.5 \mathrm{ppbv}$ (Fig. 2a). In the same timespan, the global AOD increases, reaching a value of 0.08 by 2035, similar to the global value that is reached by the direct injection of $\mathrm{SO}_{2}$ in the equatorial stratosphere in $\mathrm{SG}-\mathrm{SO} 2$; in that case, however, 
the steady-state value is reached in only 1-2 years. At the end of 2055, the increased COS emissions and $\mathrm{SO}_{2}$ injections are stopped. Average tropospheric COS concentrations follow an exponential decay guided by the tropospheric lifetime (3.8 years, due to chemistry and soil deposition), reaching a value of 1.3 ppbv after 20 years (during 2075). This means an increase of $0.8 \mathrm{ppbv}$ with respect to background condition, that would produce a direct RF negligible if compared to other well mixed greenhouse gases. The exponential decay of the stratospheric AOD in SG-COS is regulated by the stratospheric lifetime of $\mathrm{COS}\left(\sim 10\right.$ years) mainly due to reaction with $\mathrm{OH}$ and photolysis, from which stratospheric $\mathrm{SO}_{2}$ and finally sulphuric acid aerosols are formed. Therefore, the e-folding time for stratospheric AOD is longer with respect to the one resulting from SG-SO2 (Fig. 2b). In 2075, the global stratospheric AOD reaches in SG-COS a value of 0.01 , with respect to 0.003 in the background case.
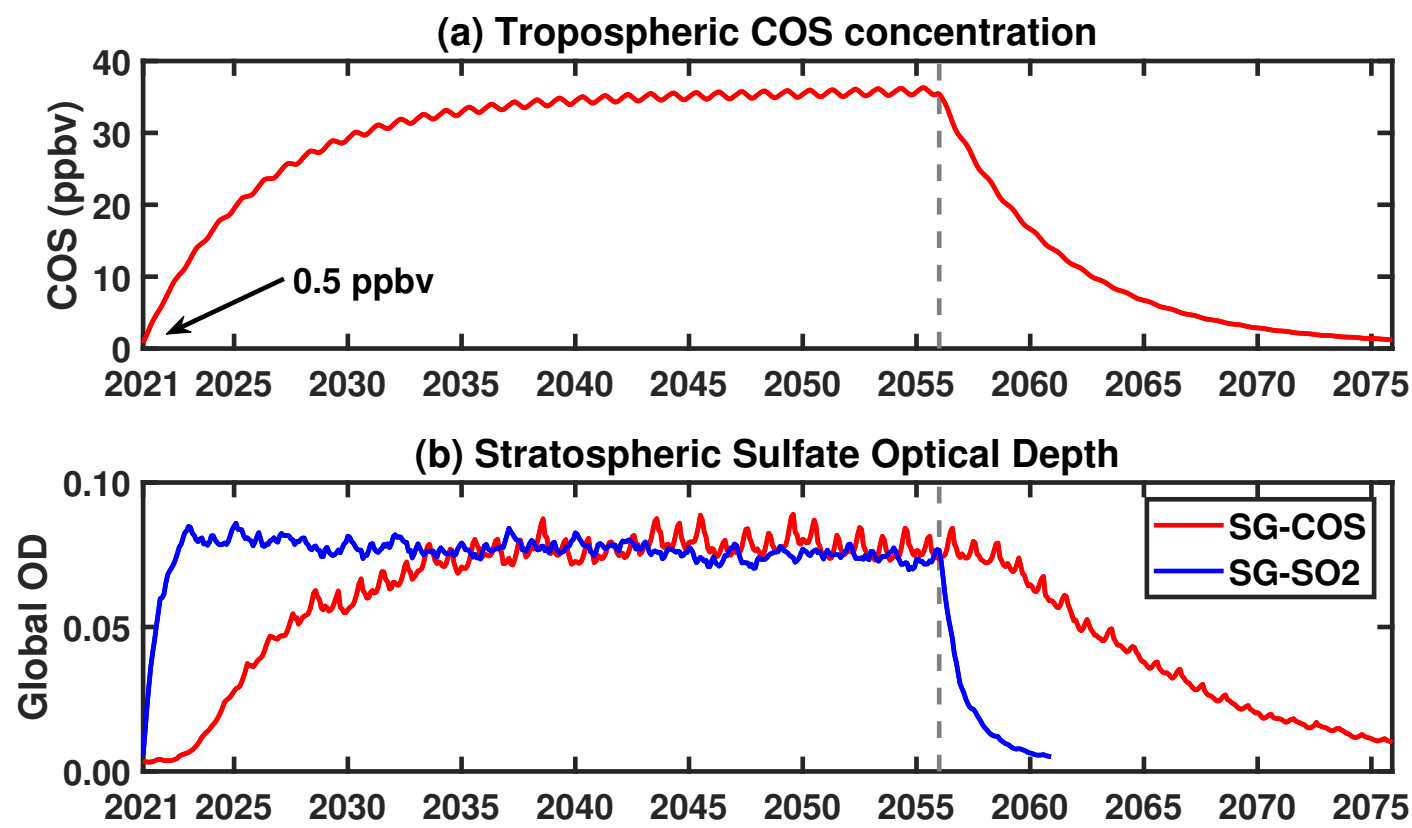

Figure 2. a) Monthly values of globally averaged tropospheric COS volume mixing ratio (ppbv) in SG-COS. The background value of 0.5 ppbv at the beginning of the simulation is highlighted. b) Globally averaged stratospheric sulfate optical depth monthly values in SG-COS (red) and SG-SO2 (blue). The grey line indicates the time when emissions of COS and $\mathrm{SO}_{2}$ are stopped, at the end of 2055. 


\subsection{Sulfate aerosol properties}

\begin{tabular}{|l|c|c|c|c|c|}
\hline & BG & SG-COS & SG-SO2 & SG-COS - BG & SG-SO2 - BG \\
\hline Total Sulfate OD & $0.055 \pm 0.003$ & $0.135 \pm 0.004$ & $0.130 \pm 0.003$ & $0.080 \pm 0.004$ & $0.075 \pm 0.004$ \\
Tropospheric Sulfate OD & $0.052 \pm 0.003$ & $0.057 \pm 0.003$ & $0.055 \pm 0.003$ & $0.005 \pm 0.004$ & $0.003 \pm 0.004$ \\
Stratospheric Sulfate OD & $0.003 \pm 0.001$ & $0.078 \pm 0.002$ & $0.075 \pm 0.001$ & $0.075 \pm 0.002$ & $0.072 \pm 0.001$ \\
Sulfate effective radius $(\mu \mathbf{m})$ & $0.18 \pm 0.01$ & $0.46 \pm 0.01$ & $0.63 \pm 0.01$ & & \\
Ice OD & $0.596 \pm 0.006$ & $0.579 \pm 0.007$ & $0.573 \pm 0.006$ & $-0.017 \pm 0.009$ & $-0.023 \pm 0.008$ \\
Ice effective radius $(\mu \mathbf{m})$ & $35 \pm 1$ & $33 \pm 1$ & $32 \pm 1$ & & \\
\hline
\end{tabular}

Table 1. Summary of calculated sulfate aerosol and cirrus ice globally-annually averaged quantities relevant for RF calculations (i.e., optical depth at $\lambda=0.55 \mu \mathrm{m}$ and effective radius). Last two columns show the calculated SG changes with respect to the BG case [years 2046-2055].

In the SG-COS experiment, surface COS fluxes are adjusted so as to have the same global aerosol optical depth (AOD) $\approx 0.08$ (see table 1). This is done in order to more easily compare the latitudinal distribution of the aerosols, and to better quantify the differences in the radiative forcing from both direct and indirect (ozone, methane and water vapor) changes in atmospheric composition.

There is a large difference in the latitudinal distribution of stratospheric sulfate optical depth, as shown in figure 3 (a). SGCOS produces an AOD more uniformly distributed over all latitudes with respect to the SG-SO2 case, where the increase of optical depth is most prominent in the tropics; this is due to the efficient tropospheric mixing of COS before it reaches the stratosphere.

The differences in the latitudinal distribution of AOD are also observable in the differences in the particle sizes and in the surface area density (SAD). Figure 3 (b) shows that the stratospheric effective radius is smaller in the SG-COS experiment and uniform for all latitudes, with a global value of $0.46 \mu \mathrm{m}$. In SG-SO2, the effective radius is higher in the tropics $(0.63 \mu \mathrm{m})$; AOD is also larger in the tropics in that case, due to a larger concentration of particles there, even if larger particles are less effective at scattering incoming solar radiation (English et al., 2012).

Figure 4 shows a comparison of the effective radius (a) and SAD (b) between the BG, SG-COS and SG-SO2 cases, separating the tropics, mid-latitudes and polar regions. $\mathrm{As}_{\mathrm{SO}_{2}}$ is injected at the equator, all oxidation and nucleation happens in the tropics in SG-SO2. This is reflected in the vertical distribution which has a maximum in the lowermost stratosphere. On the other hand in SG-COS, the effective radius increase is reached at higher altitudes, between $18-30 \mathrm{~km}$, which is consistent with COS reaching higher altitudes through deep tropical convection before it is photochemically destroyed (Barkley et al., 2008). The same explanation is valid for the tropical SAD in panel (b).

As the size of the particles is determined by nucleation in the tropical region, where $\mathrm{SO}_{2}$ oxidation occurs, mid-latitude and polar behaviour of the aerosols depends on the polewards transport by the Brewer-Dobson Circulation (BDC). 
In SG-SO2, aerosols grow rapidly in the tropical region due to the high concentration of $\mathrm{SO}_{2}$, and their larger size affects sedimentation rates, thus decreasing their lifetime. Consequently, the amount of aerosols transported to higher latitudes is lower; in SG-COS, smaller particles with a higher lifetime are either easily transported towards the poles or directly formed there. Smaller particles at a higher concentration, and larger particles at a lower concentration may then result in a SAD which looks similar at mid-latitudes and polar region, but for different reasons.

The vertical distribution of particles and their optical properties are shown in Figure 5 (see Fig. $\mathrm{S} 2$ for $\mathrm{COS}, \mathrm{SO}_{2}$ and $\mathrm{SO}_{4}$ concentration changes). The vertical distribution of the $\mathrm{SAD}$ is fundamental to understand the role of the heterogeneous reaction and their effect on stratospheric ozone. The baseline case in panels (a) and (b) are a reference for understanding their changes in SG-COS (panels (c) and (d)). The particles transported via the BDC to the poles are large enough to efficiently scatter solar radiation so that the SAD and extinction changes show a similar behaviour, with a global increase of stratospheric values with maxima at higher latitudes between $15-25 \mathrm{~km}$.

Panels (f) and (d) show the extinction and SAD changes between the two SG experiments, to underline that in SG-SO2 extinction of the radiation is confined in the tropical stratosphere between $15-25 \mathrm{~km}$, meaning a negative change in SG-COS. As discussed before, the formation of larger particles in SG-SO2 in the tropical region reduces the amount of aerosol transported to the poles compared to the SG-COS case, where a larger number of smaller particles produces a positive change in SAD and, consequently, in extinction.

\subsection{Deposition}

\begin{tabular}{|l|c|c|c|c|c|c|c|}
\hline Experiment & MSA & SO $_{2}$ & SO $_{4}$ & COS & CS $_{2}$ & H2S & Total \\
\hline BG & $1.0 \pm 0.1$ & $35.2 \pm 1.4$ & $9.4 \pm 0.4$ & $0.39 \pm 0.01$ & $0.47 \pm 0.03$ & $1.5 \pm 0.1$ & $48.0 \pm 1.8$ \\
SG-SO2 & $1.0 \pm 0.1$ & $35.6 \pm 1.5$ & $9.5 \pm 0.4$ & $0.39 \pm 0.01$ & $0.47 \pm 0.03$ & $1.5 \pm 0.1$ & $48.5 \pm 1.8$ \\
SG-COS & $1.0 \pm 0.1$ & $36.4 \pm 1.5$ & $9.9 \pm 0.4$ & $31.6 \pm 0.1$ & $0.47 \pm 0.03$ & $1.5 \pm 0.1$ & $80.9 \pm 1.7$ \\
\hline
\end{tabular}

Table 2. Globally-annually averaged dry deposition rates of sulfur species (Tg-S/yr) [years 2046-2055]. 

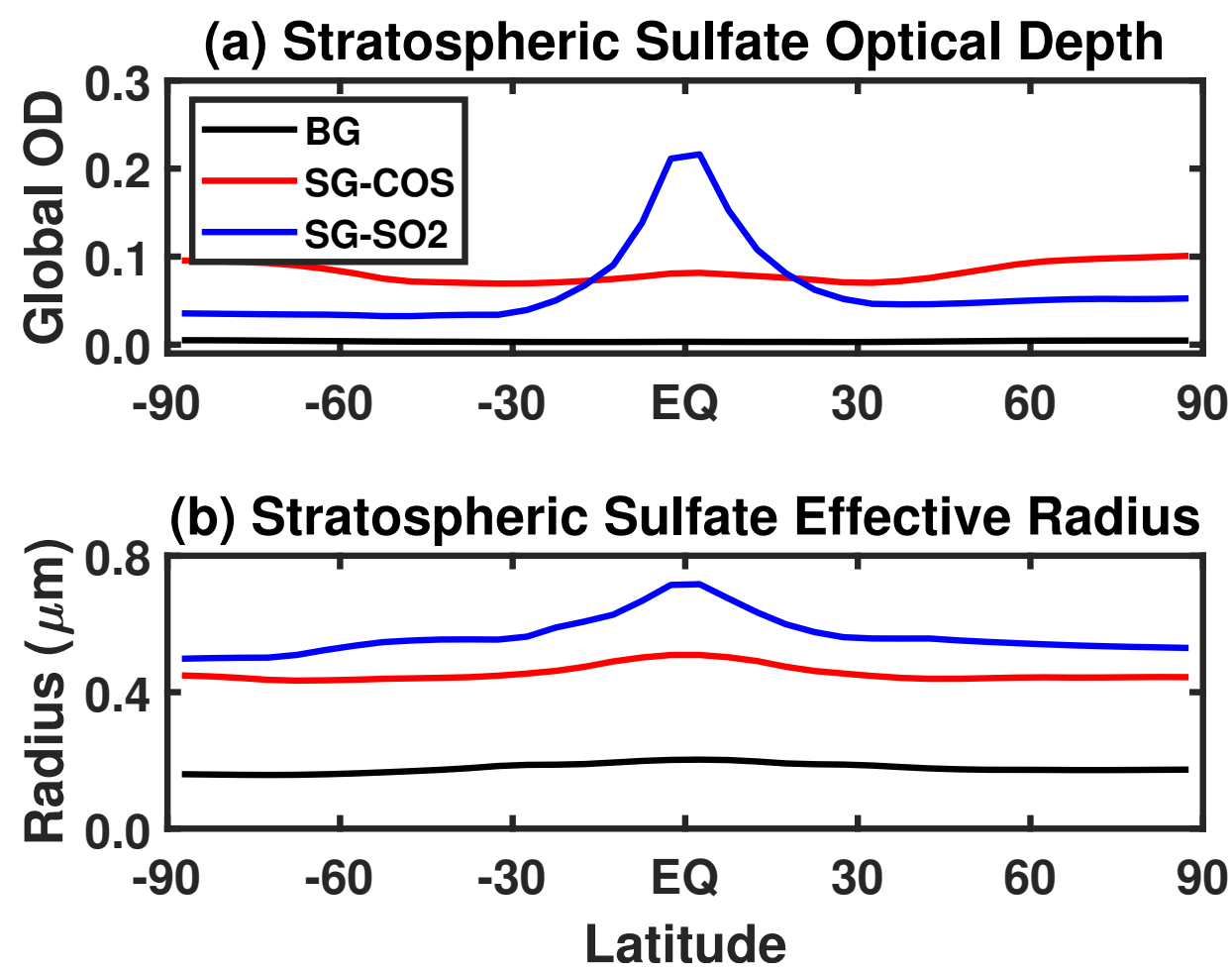

Figure 3. a) Latitudinal distribution of zonal mean values of stratospheric sulfate optical depth for the BG (black), SG-COS (red) and SG$\mathrm{SO} 2$ (blue) cases. b) Stratospheric effective radius (in $\mu \mathrm{m}$ ) (from tropopause to $6 \mathrm{hPa}$ ). All quantities are annually averaged over the years 2046-2055

\begin{tabular}{|l|c|c|c|c|c|}
\hline Experiment & MSA & SO $_{2}$ & SO $_{4}$ & Total & Net [sources-sinks] \\
\hline BG & $1.5 \pm 0.1$ & $3.0 \pm 0.1$ & $43.2 \pm 1.5$ & $47.7 \pm 1.6$ & $+0.3 \pm 0.1$ \\
SG-SO2 & $1.5 \pm 0.1$ & $3.2 \pm 0.1$ & $46.5 \pm 1.5$ & $51.2 \pm 1.6$ & $+0.5 \pm 0.1$ \\
SG-COS & $1.5 \pm 0.1$ & $3.4 \pm 0.1$ & $49.4 \pm 1.5$ & $54.3 \pm 1.6$ & $+0.8 \pm 0.1$
\end{tabular}

Table 3. Globally-annually averaged wet deposition rates of sulfur species (Tg-S/yr) [years 2046-2055]. The last column shows the net balance of total sulfur sources and sinks (Tg-S/yr).

The enhancement of the stratospheric sulfate burden would produce an increase in sulfur deposition, in dry form through acid gas deposition and in wet form through rain, fog and aerosol particles.

Acid deposition may damage human health when high concentrations of particles with a diameter below certain thresholds (PM2.5 and PM10) are inhaled. The acidification of soils and water may damage plants, microorganisms and aquatic animals, 
(a) Sulfate Effective Radius
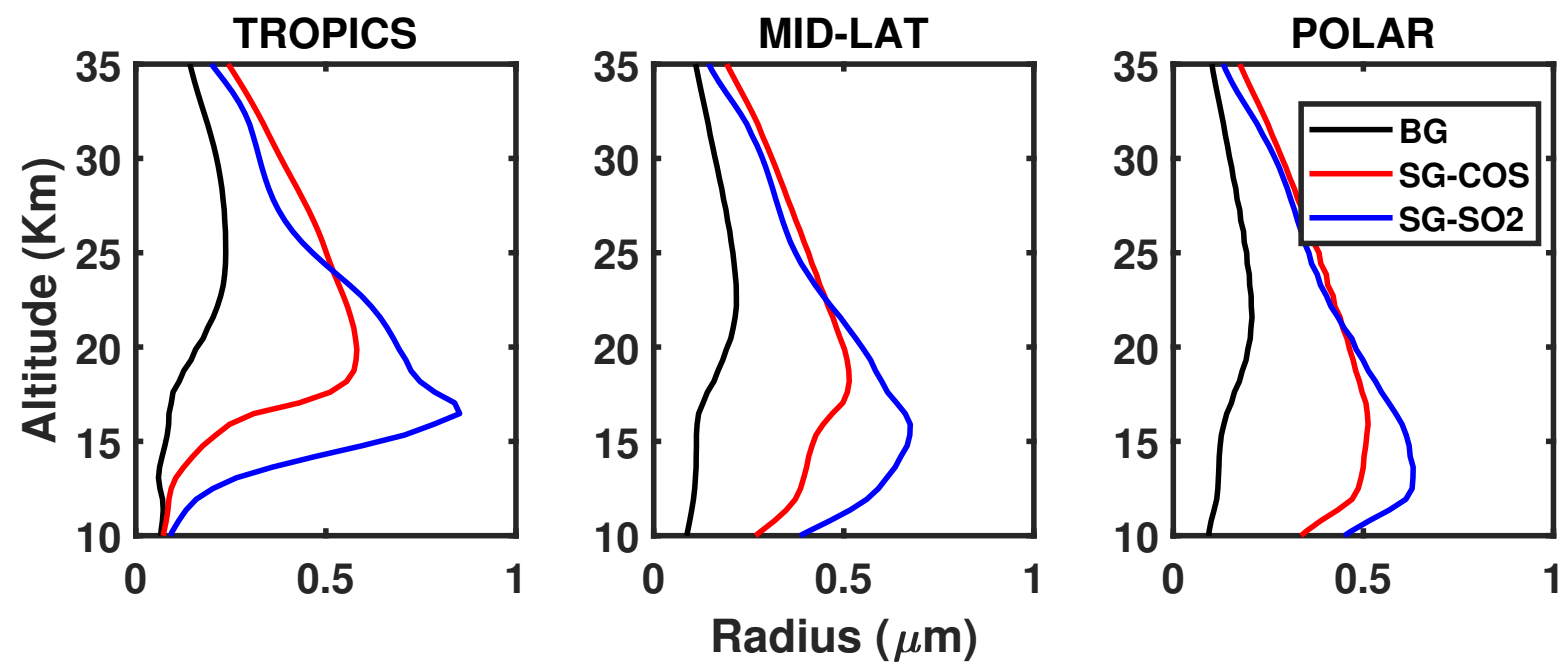

(b) Sulfate SAD
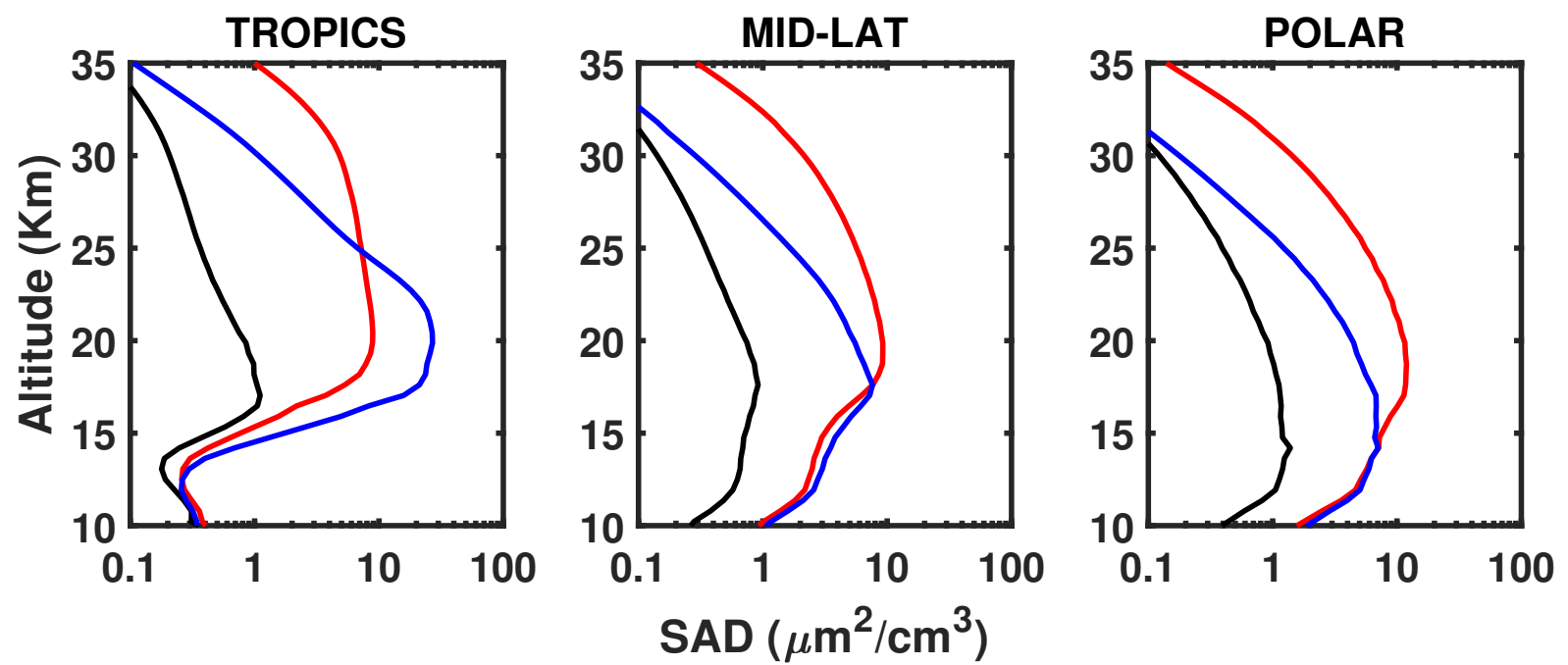

Figure 4. Vertical profiles of sulfate effective radius (in $\mu \mathrm{m}$, a) and surface area density (in $\left.\mu \mathrm{m}^{2} / \mathrm{cm}^{3}, \mathrm{~b}\right)$ at different latitudinal bands $(20 \mathrm{~N}$ 20S for the Tropics, 30-50 at both $\mathrm{N}$ and $\mathrm{S}$ for the Mid-lat and 60-90 at both $\mathrm{N}$ and $\mathrm{S}$ for the Polar plots). All quantities are annually averaged over the years 2046-2055. 
(a) Sulfate Extinction at $550 \mathrm{~nm}$

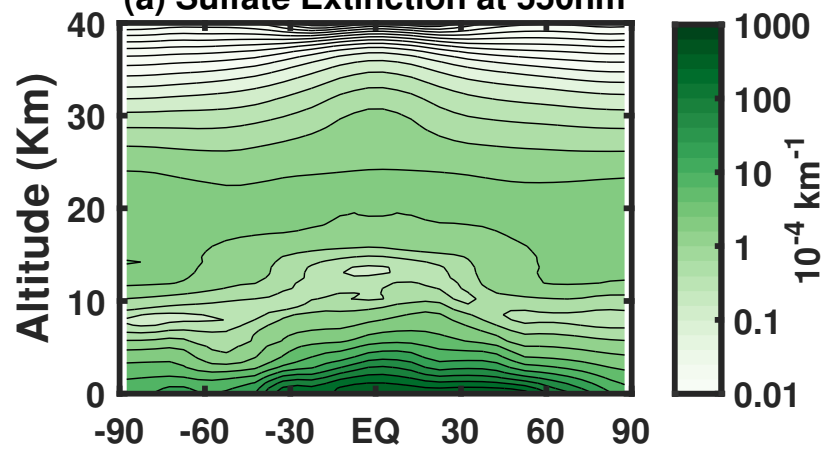

(c) Ext Change [SG-COS - BG]

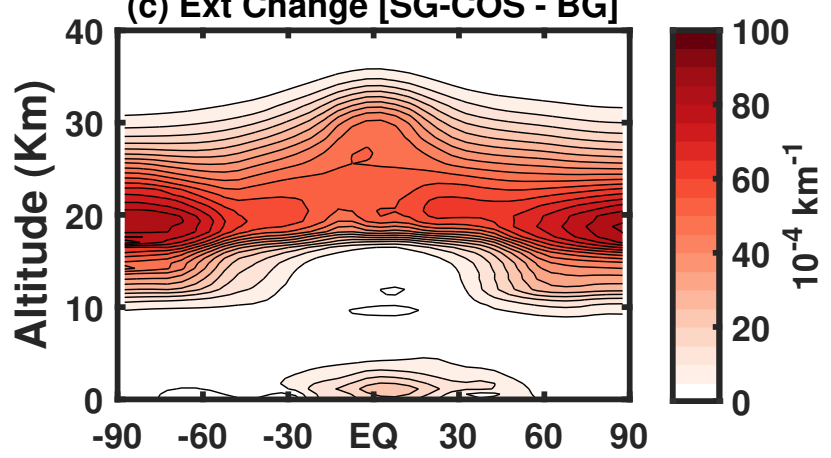

(e) Ext Change [SG-COS - SG-SO2]

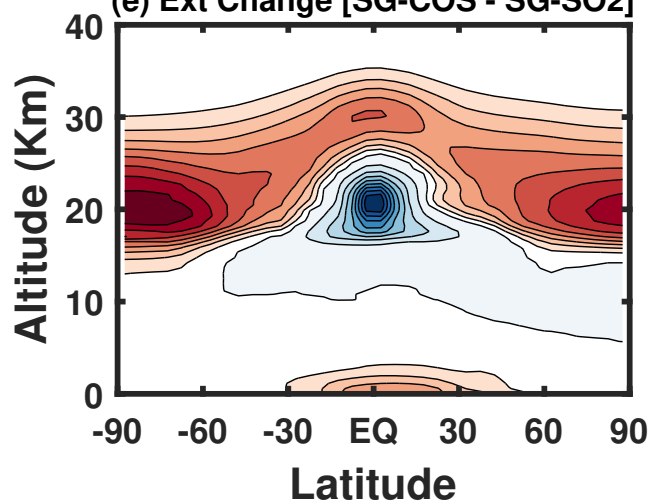

(b) Sulfate SAD

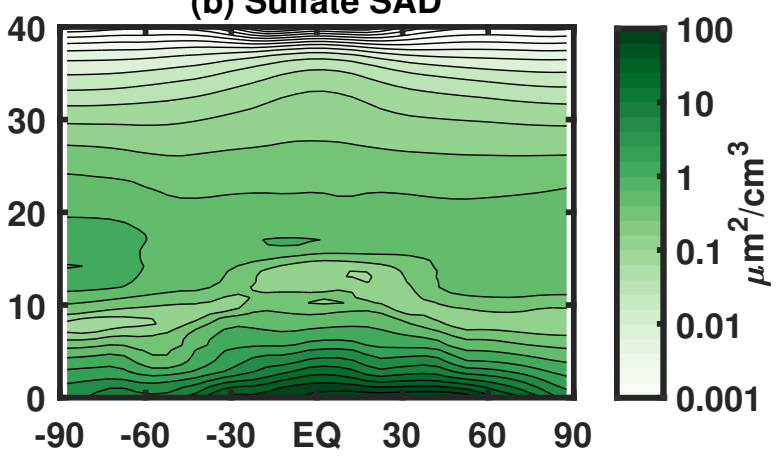

(d) SAD Change [SG-COS - BG]
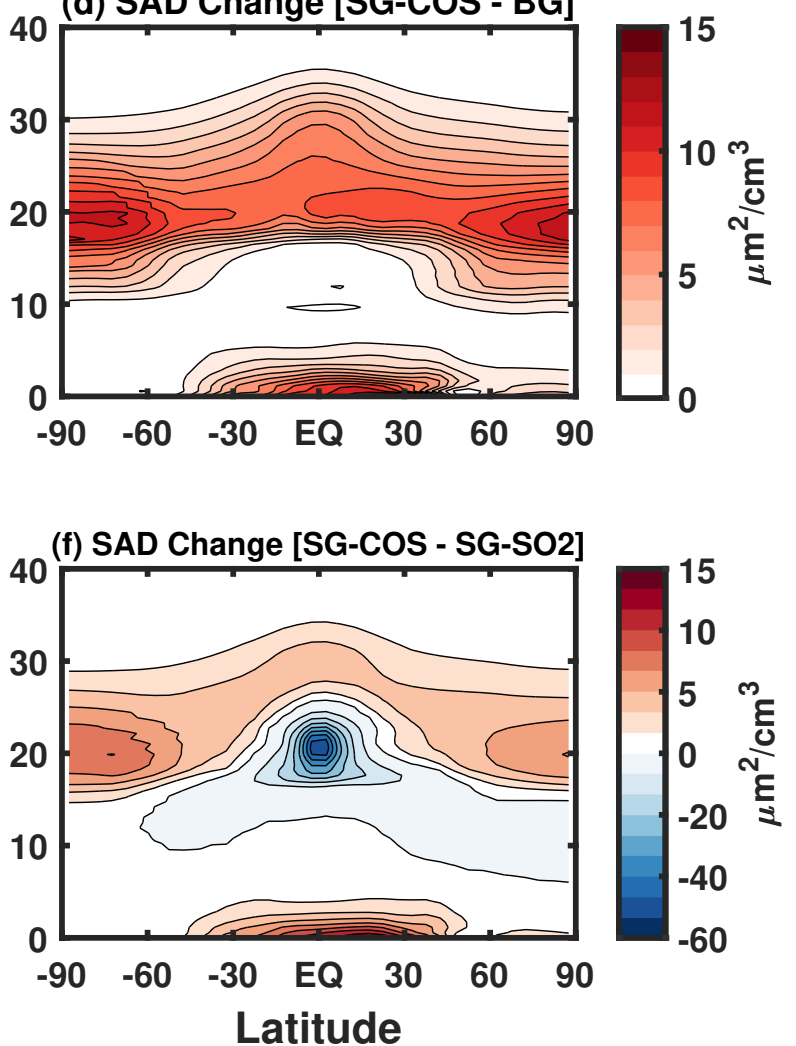

Figure 5. Zonal mean values of sulfate extinction (in $10^{-4} \mathrm{~km}^{-1}$ ) and SAD (in $\mu \mathrm{m}^{2} / \mathrm{cm}^{3}$ ) in BG (panels a and b, respectively) and their change in the case of the SG-COS experiment (panels $c$ and d). Panels e) and f) show extinction and SAD changes between SG-COS and SG-SO2. All quantities are annually averaged over the years 2046-2055. 
but the impact on the ecosystem depends on the rate at which acidifying compounds are deposited from the atmosphere, compared with the rate at which acid neutralizing capacity (ANC) is generated within the ecosystem (Driscoll et al., 2001).

Here we analyse how dry and wet deposition of sulfur species are distributed globally as a result of the two SG interventions. Table 2 and 3 summarize wet and dry deposition rates for the SG-COS and BG experiments, respectively, and they include the contribution of each species to the total deposition. In particular, in SG-COS the increase in COS fluxes produces both an increase in sulfuric deposition, after its photolysis and oxidation to sulfuric acid, and in dry deposition of COS itself, as it is removed to the ground through uptake by vegetation and soils (Kettle et al., 2002).

The global distribution of COS deposition for the baseline case is shown in figure 6(a) while the increase in deposition from the SG-COS experiment is shown in figure 6(b). COS uptake by plants is concentrated mainly in the tropical rainforests of South America, Africa, and southeast Asia and boreal coniferous forests across North America, northern Europe, and northern Asia. Uptake by soils occurs mainly in arid and semiarid regions, such as savanna regions in the northern and southern Africa and in the southwestern regions of North America, in the pampas of Argentina, in Australia, and in the steppes of central Asia (Kettle et al., 2002). Dry deposition of COS doesn't contribute to acid deposition and, currently, there is no information available on how different soils or ecosystems would be affected by higher local COS concentrations; therefore, we assumed that their uptake efficiency does not change. The robustness of this assumption will need to be studied.

The global distribution of $\mathrm{SO}_{x}$ deposition is also shown in figure 6. Panels (c) and (d) show dry and wet deposition, respectively, for the background case. Dry deposition maxima are localized in urban areas close to the source where the emitted sulfur dioxide is immediately oxidized, while wet deposition distribution depends both on sulfate concentration and precipitation.

Panels (e) and (f) show the total $\mathrm{SO}_{x}$ deposition change in SG-COS with respect to the baseline case, in absolute terms and as a percentage of the baseline case, and most of its increase is due to wet deposition (see tables 2 and 3, and see Tables S1-4 for a breakdown of global sources and sinks of sulfur species). In both figures, the distribution of deposition is more uniform over the globe with respect to the tropical injection of $\mathrm{SO}_{2}$, except for the polar regions, because of the reduced precipitation rates. Consequently, figure 6 (f) shows a large increase in percent deposition in the polar region (17\% in the Arctic, $8 \%$ in Antarctic) because of very low values in the baseline case. On the other hand, deposition change is close to zero in polluted regions.

Globally, the annual differences in deposition fluxes for all species compared to the background case amount to $8.3 \pm 0.2$ $\mathrm{Tg}-\mathrm{S} / \mathrm{yr}$ for SG-COS and $3.9 \pm 0.2 \mathrm{Tg}-\mathrm{S} / \mathrm{yr}$ for SG-SO2, which equates to an increase of $8.9 \pm 0.3 \%$ and $4.2 \pm 0.3 \%$, respectively. 

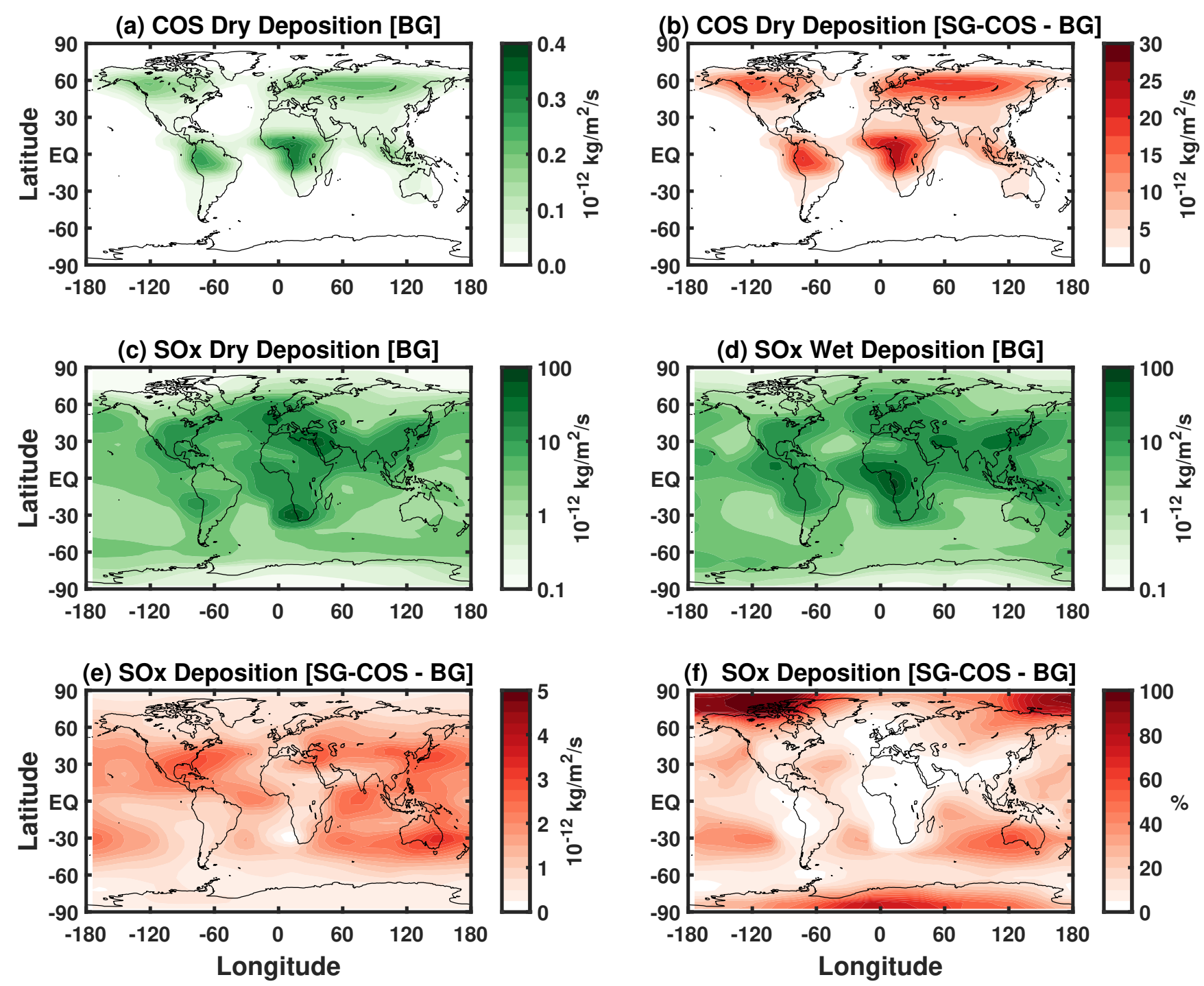

Figure 6. a) Surface dry deposition fluxes $\left(10^{-12} \mathrm{~kg} / \mathrm{m}^{2} / \mathrm{s}\right)$ of COS in the background case. b) Change in COS dry deposition fluxes in SGCOS compared to a). c) $\mathrm{SO}_{x}$ dry deposition fluxes $\left(10^{-12} \mathrm{~kg} / \mathrm{m}^{2} / \mathrm{s}\right)$ in the background case. d) $\mathrm{SO}_{x}$ dry deposition fluxes $\left(10^{-12} \mathrm{~kg} / \mathrm{m}^{2} / \mathrm{s}\right)$ in the background case. e) Change in $\mathrm{SO}_{x}$ total deposition fluxes in SG-COS compared to the background. f) as e) but in \% of the background values. 


\section{Indirect effects}

\begin{tabular}{|l|c|c|c|c|c|}
\hline & BG & SG-COS & SG-SO2 & SG-COS - BG & SG-SO2 - BG \\
\hline $\begin{array}{l}\text { COS [troposphere] } \\
\text { (ppbv) }\end{array}$ & $0.47 \pm 0.1$ & $35.5 \pm 0.2$ & $0.47 \pm 0.1$ & $35.1 \pm 0.2$ & $0.00 \pm 0.1$ \\
CH4 lifetime (yr) & $8.72 \pm 0.13$ & $9.83 \pm 0.18$ & $9.78 \pm 0.20$ & $\begin{array}{c}1.11 \pm 0.13 \\
{[(+12.7 \pm 1.4) \%]}\end{array}$ & $\begin{array}{c}1.06 \pm 0.17 \\
{[(+12.2 \pm 2.0) \%]}\end{array}$ \\
$\begin{array}{l}\text { H2O [stratosphere] } \\
\text { (ppmv) }\end{array}$ & $6.01 \pm 0.08$ & $5.87 \pm 0.17$ & $6.02 \pm 0.14$ & $-0.14 \pm 0.11$ & $0.01 \pm 0.08$ \\
O3 column (DU) & $288.9 \pm 1.7$ & $293.8 \pm 1.5$ & $290.4 \pm 1.6$ & $4.9 \pm 2.2$ & $1.5 \pm 1.7$ \\
\hline
\end{tabular}

Table 4. Summary of calculated sulfate aerosol and cirrus ice globally-annually averaged quantities relevant for RF calculations (i.e., optical depth at $\lambda=0.55 \mu \mathrm{m}$ and effective radius). Last two columns show the calculated SG changes with respect to the BG case [years 2046-2055].

\begin{tabular}{|c|c|c|c|c|c|}
\hline & $\begin{array}{c}\text { BG } \\
\left(\mathbf{W} / \mathbf{m}^{2}\right)\end{array}$ & $\begin{array}{c}\text { SG-COS } \\
\left(\mathbf{W} / \mathbf{m}^{2}\right)\end{array}$ & $\begin{array}{c}\text { SG-SO2 } \\
\left(\mathbf{W} / \mathbf{m}^{2}\right)\end{array}$ & $\begin{array}{c}\text { SG-COS - BG } \\
(\boldsymbol{\%})\end{array}$ & $\begin{array}{c}\text { SG-SO2 - BG } \\
(\boldsymbol{\%})\end{array}$ \\
\hline UVB & $0.208 \pm 0.002$ & $0.199 \pm 0.001$ & $0.203 \pm 0.001$ & $-4.3 \pm 0.6$ & $-2.4 \pm 0.9$ \\
\hline UVA & $11.43 \pm 0.01$ & $11.20 \pm 0.01$ & $11.25 \pm 0.01$ & $-2.0 \pm 0.1$ & $-1.6 \pm 0.1$ \\
\hline
\end{tabular}

Table 5. Summary of calculated globally-annually averaged quantities of UVB and UVA at surface. Last two columns show the calculated SG percentage changes with respect to the BG case [years 2046-2055].

The simulated enhancement in the stratospheric aerosol layer would produce two main effects: an increased scattering of solar radiation, that in turn would reduce surface temperatures, and the local absorption of more near-infrared solar and terrestrial radiation, that would warm the stratospheric layer where the aerosols reside (as observed for volcanic eruptions, see Lacis et al., 1992; Labitzke and McCormick, 1992). Furthermore, the increase in the surface area density of the aerosols would affect the heterogeneous chemistry of $\mathrm{ClO}_{x}$ and $\mathrm{NO}_{x}$ with implications for ozone concentration and UV radiation at the surface (Tilmes et al., 2009, 2018b, 2021).

For $\mathrm{SO}_{2}$, it has been shown that the combination of surface cooling, perturbation of stratospheric temperatures and changes in tropospheric ozone and in UV at the surface also affects methane lifetime (Visioni et al., 2017a). In this section we analyse the differences in these changes also for the SG-COS experiment.

Figure 7 shows the ozone changes in the two SG experiments with respect to the BG case. Panels (a) and (b) show the monthly total ozone column changes as a function of latitude. Close to the equator there is a small reduction in the overall 
column, mostly due to a reduction in tropospheric ozone, as visible in panels (c) and (d), as a direct consequence of the surface cooling (Nowack et al., 2016). On the other hand, at higher latitudes an overall increase in the total column is observable due to an increase in stratospheric ozone. This is particularly evident closer to the poles.

During springtime months, there is some Antarctic ozone depletion, while in the Arctic a recovery of ozone is observable. In the Antarctic spring, the polar vortex is strengthened by the stratospheric heating in the tropics that affects the equator-topole thermal wind balance (Visioni et al., 2020), resulting in greater confinement of cold air, that, in turn, enhances the ozone depletion by the polar stratospheric clouds (PSC). The tropical stratospheric heating is higher in SG-SO2 with respect to SG$\mathrm{COS}$ as the aerosols are less confined (fig. S4). Consequently, the strengthening of polar vortex in SG-SO2 produces a higher ozone depletion. In the Arctic, on the other hand, PSC-related ozone loss is lower (Tilmes et al., 2018a), and the predominant effect is that from an acceleration of the BDC transporting ozone-rich air from lower latitudes.

Panels (c) and (d) show the annual mean of ozone mixing ratio percentage change as a function of altitude and latitude. In both SG experiments, negative changes below the tropopause are governed by the decrease in solar radiation which comes into play in the photo-dissociation reaction of $\mathrm{NO}_{x}$ as an ozone precursor $\left(\mathrm{NO}_{2}+\mathrm{h} \nu \quad(\lambda<420 \mathrm{~nm}) \rightarrow \mathrm{NO}+{ }^{3} \mathrm{O}\right)$. Sunlight reduction also affects the $\mathrm{O}_{3}$ photolysis, decreasing the ozone loss. Positive changes are due to the balance of the previous reactions and the increase of methane (see table 4) as a source of ozone in its oxidation chain, and mainly due to the decrease of the tropospheric water vapour in a clean air environment (low $\mathrm{NO}_{x}$ ), such as the tropics (Nowack et al., 2016; Xia et al., 2017b).

Above the tropopause, there is a negative ozone change in the lower stratosphere in both SG experiments, except for the Arctic region where we observe a small increase in the Arctic lowermost stratosphere in both cases. The key drivers of stratospheric ozone change are the increase in heterogeneous reactions, as a result of the enhancement of stratospheric aerosols, and the perturbation of the dynamics governing ozone transport.

Negative ozone changes correspond to the region where the SAD reaches its maximum values (fig. 5 (d) and (f)): between $10-20 \mathrm{~km}$ in the polar regions for SG-COS and mainly between $15-25 \mathrm{~km}$ at tropics for SG-SO2. The increase of the SAD enhances heterogeneous chemistry and results in denitrification via hydrolysis of dinitrogen pentoxide $\left(\mathrm{N}_{2} \mathrm{O}_{5}+\mathrm{H}_{2} \mathrm{O} \stackrel{\mathrm{M}}{\longrightarrow}\right.$ $2 \mathrm{HNO}_{3}$ ). The loss of $\mathrm{NO}_{x}$ decreases the rate of ozone depletion through its catalytic cycle. Whereas in the mid-stratosphere, where the cycles of chlorine $\left(\mathrm{ClO}_{x}\right)$ and bromine $\left(\mathrm{BrO}_{x}\right)$ are dominant, there is an increase in ozone loss since reduction of $\mathrm{NO}_{x}$, that normally bounds chlorine $\left(\mathrm{ClONO}_{2}\right)$, allows $\mathrm{ClO}$ to destroy more ozone (Tilmes et al., 2018b; Grant et al., 1992).

At low latitudes, stratospheric ozone concentration is also driven by change of tropical upwelling (Visioni et al., 2021): the reduction of tropical upwelling of ozone-poor air coming from the lowermost stratosphere leads to higher ozone concentration at altitudes of about 20-22 km (Tilmes et al., 2018b).

Figure S5 (e) shows the change of tropical upwelling in relation to change of the residual vertical velocity ( $\mathrm{w}^{*}$ ) with respect to the baseline case. Negative $\mathrm{w}^{*}$ anomalies in SG-COS mean weaker tropical upwelling as consequence of tropospheric cooling. In SG-SO2, the highest concentration of absorbing aerosols leads to positive $\mathrm{w}^{*}$ above $20 \mathrm{~km}$ due to the local warming but this doesn't affect the transport of ozone-poor air from the lower layers. 
Above the discussed altitudes, there is a net ozone production in both SG experiments, with an higher increase of ozone mixing ration in SG-COS experiment with respect to SG-SO2, especially in the extra-tropical region. Ozone depletion at these altitudes is mainly controlled by the catalytic cycle of $\mathrm{NO}_{x}$, that is inhibited by the denitrification process due to heterogeneous reactions on aerosols.

Globally, the annually-averaged ozone column increases of 4.9 and 1.5 DU for SG-COS and SG-SO2, respectively (table 4). The stratospheric ozone increase affects UVB at the surface due to its photodissociation, while aerosol could affect UVA radiation by scattering processes: the projected changes are shown in figure 8 for both UVA and UVB. We estimated these changes using TUV (from https://www2.acom.ucar.edu/modeling/tropospheric-ultraviolet-and-visible-tuv-radiation-model), using in input our model latitudinal and monthly values for the period (2046-2055) for aerosol optical depth, total ozone column, climatological cloud cover and surface albedo.

In both SG experiments, the negative changes of UVB radiation at surface, except in the Antarctic region, are related to the variation in stratospheric ozone. as well as the interannual variation that increase towards the poles, due to the seasonal variation of ozone, as discussed before. UVA decrease is everywhere negative in both SG experiments. In particular, the correlation between UVA change and particles scattering is evident if we compare this latitudinal distribution with the stratospheric AOD of figure 3(a). The globally averaged UVB and UVA changes at surface are summarized in table 5.

Methane is an indirect source of tropospheric ozone (West and Fiore, 2005), and it is also a greenhouse gas. Knowing its variation is fundamental to understand the final contribution to the radiative forcing that one would wish to achieve with this geoengineering method. From table 4, we measure a global increase in methane lifetime of $12.7 \%$ in SG-COS and $12.2 \%$ in SG-SO2, which we can identify in the increase in methane itself. The reason for the increase in methane is to be found in the behaviour of the hydroxyl radical $(\mathrm{OH})$, as the main sink of methane is the oxidation reaction with $\mathrm{OH}$ : decrease of $\mathrm{OH}$ means an increase of methane lifetime. As discussed by Visioni et al. (2017b), mechanisms that cause an increase in $\mathrm{OH}$ are as follows: (a) surface cooling lessens the amount of tropospheric water vapor and inhibits the temperature-dependent reaction of $\mathrm{NO}+\mathrm{O}_{3}$; (b) decrease of tropospheric UV, due to enhancement of ozone and scattering radiation, reduce $\mathrm{O}\left({ }^{1} \mathrm{D}\right)$ that takes part of the reaction $\mathrm{O}\left({ }^{1} \mathrm{D}\right)+\mathrm{H}_{2} \mathrm{O} \rightarrow 2 \mathrm{OH}$; (c) increase of SAD enhances heterogeneous chemistry reducing the amount of $\mathrm{NO}_{x}\left(\mathrm{NO}+\mathrm{HO}_{2}, \mathrm{NO}+\mathrm{RO}_{2}\right)$; (d) increase of tropical lower stratosphere temperature (TTL) that regulates the stratospheretroposphere exchange, which can be positive or negative depending on the net result of the superimposed species $\left(\mathrm{CH}_{4}, \mathrm{NO}_{y}\right.$, $\mathrm{O}_{3}, \mathrm{SO}_{4}$ ) in the extratropical upper troposphere-lower stratosphere (UTLS).

The warming of the TTL is shown in figure S5 (d): in SG-SO2, larger particles confined in the tropical region produce a greater warming of the TTL with respect to smaller ones distributed all over the globe in SG-COS. The role of dimensions and distributions of aerosols in stratospheric warming is confirmed by the heating rates, as shown in figure S4. 

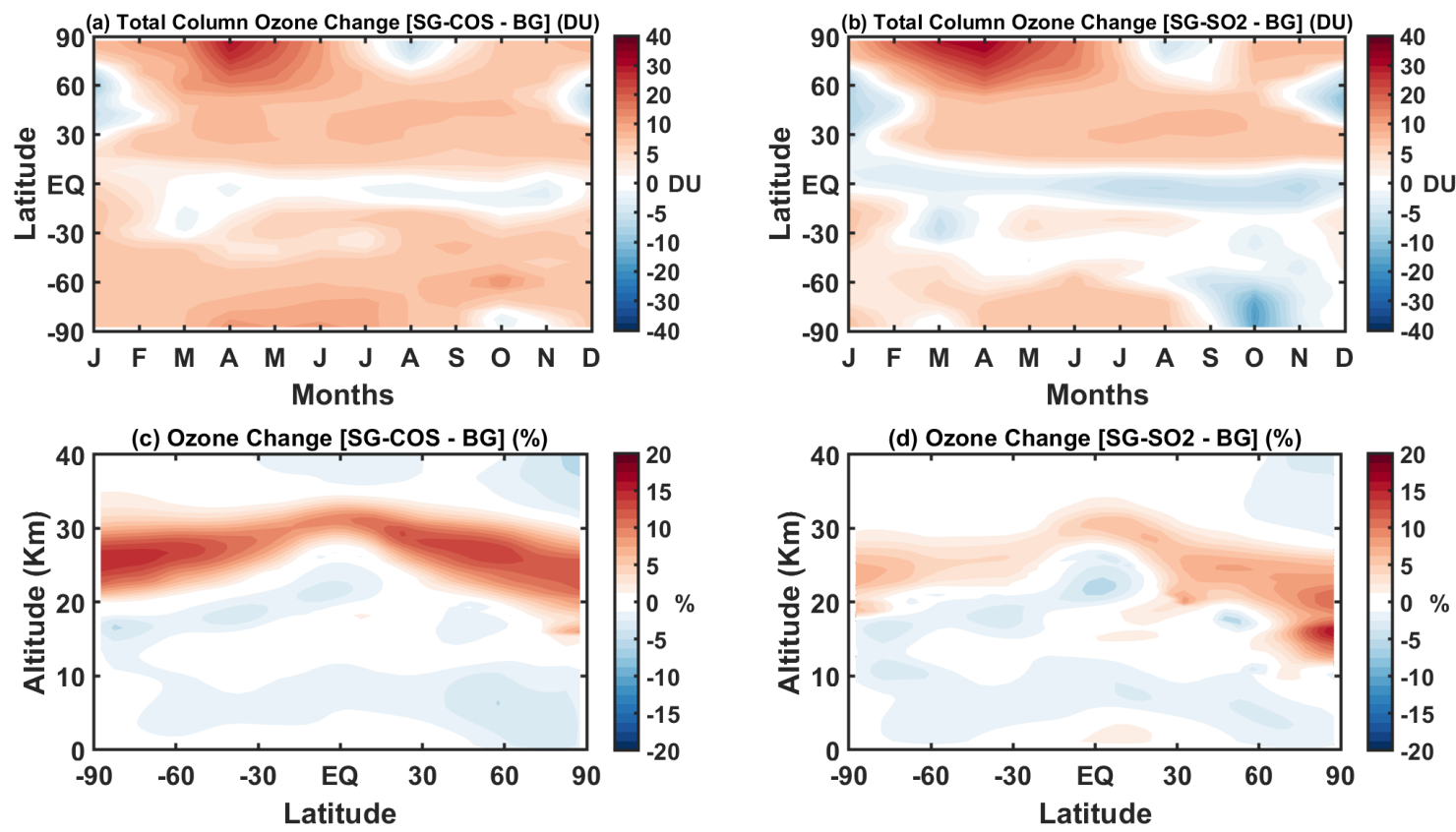

Figure 7. a,b) Monthly mean zonal values of SG ozone total column changes (DU) with respect to the BG case for SG-COS and SG-SO2 respectively. c, d) ozone mixing ratio percent changes with respect to the BG case. All quantities are annually averaged over the years 2046-2055.

\section{Radiative forcing}

\begin{tabular}{|l|c|c|c|}
\hline Total RF $\left(\mathbf{W} / \mathbf{m}^{2}\right)$ & SW & LW & NET \\
\hline SG-COS & $-1.47 \pm 0.12$ & $+0.18 \pm 0.25$ & $-1.29 \pm 0.13$ \\
SG-SO2 & $-1.57 \pm 0.10$ & $-0.13 \pm 0.23$ & $-1.70 \pm 0.13$ \\
\hline
\end{tabular}

Table 6. Globally-annually averaged total RF of sulfate aerosols and greenhouse gases for the two SG experiments with respect to BG (shortwave, longwave and net) $\left(\mathrm{W} / \mathrm{m}^{2}\right)$ [years 2046-2055].

The ULAQ-CCM radiative transfer module calculates online the radiative forcing due to aerosols, greenhouse gases (GHGs), and low and high clouds. The effects of single components have been estimated offline for both shortwave (SW) and longwave (LW) with the same radiative transfer core, for sulfate aerosols, clouds, $\mathrm{COS}, \mathrm{CH}_{4}$, stratospheric $\mathrm{H}_{2} \mathrm{O}$, stratospheric and tropospheric $\mathrm{O}_{3}$ in order to properly separate the contributions.

Tables S7 and S8 summarise the individual contributions of GHGs changes for SG-COS and SG-SO2, respectively. Similar increases of methane in both SG experiments produce the same positive LW RF; the TTL warming (which results in an 

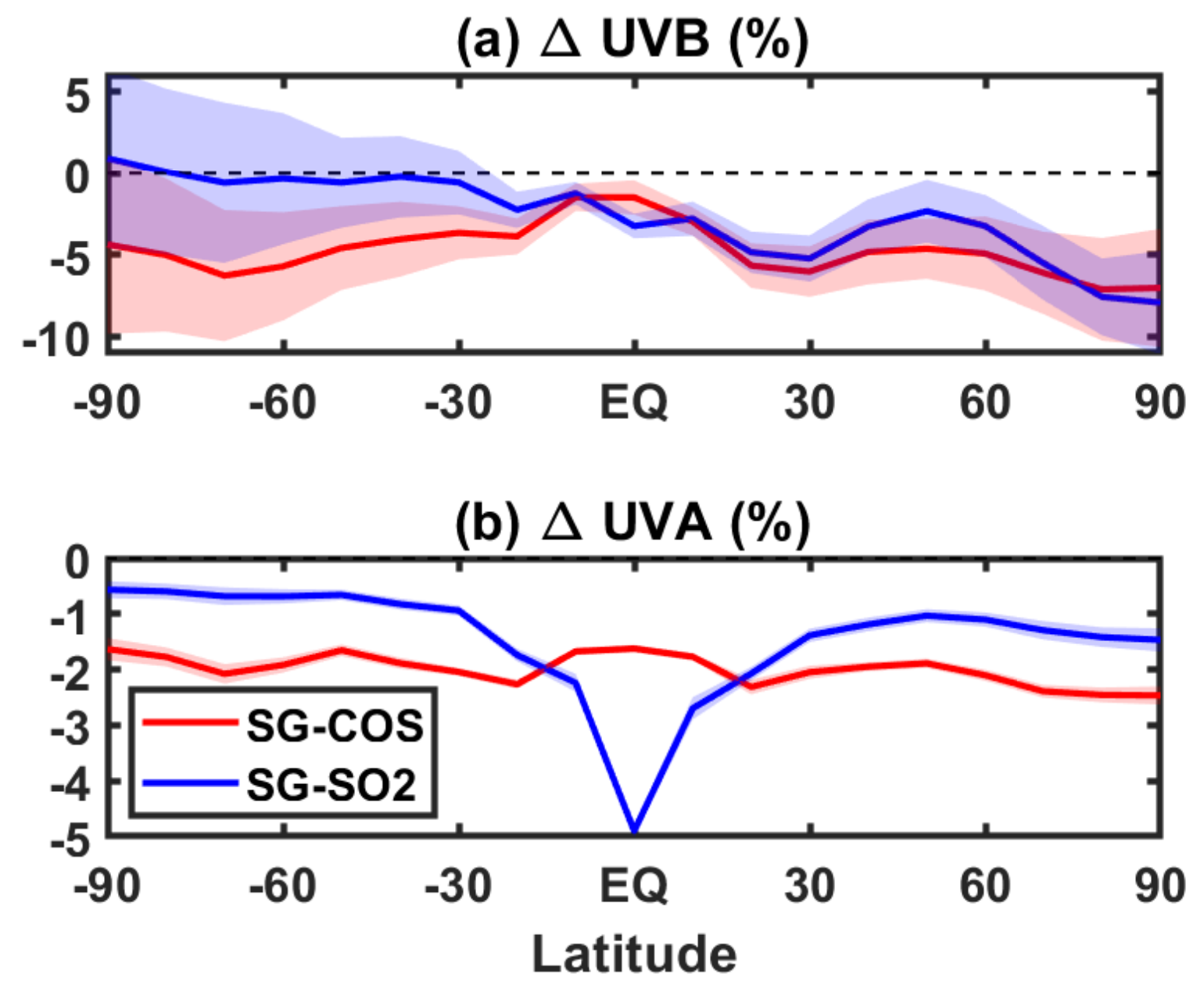

Figure 8. Mean zonal UVB and UVA percent changes at surface with respect to BG case (panels a and b, respectively) in SG-COS (red) and SG-SO2 (blue). All quantities are annually averaged over the years 2046-2055. 
increase in stratospheric water vapor), results in a small but positive contribution from $\mathrm{H}_{2} \mathrm{O}$ in SG-SO2. Contributions from both stratospheric and tropospheric $\mathrm{O}_{3}$ changes have also been estimated, but are negligible.

In SG-COS, obviously, the increase of COS concentration, which is a GHG, must be taken into account. We estimated its contribution to RF based on the definition of global warming potential (GWP) on a mass/mass basis as in Bruhl et al. (2012) for a time horizons of 30 years (2021-2050). GWP can be approximated as follows by the expression of Roehl et al. (1995), assuming that the perturbation of the radiation balance of the Earth by greenhouse gases $\mathrm{COS}$ and $\mathrm{CO}_{2}$ decays exponentially after a pulse emission for a time horizon $\Delta \mathrm{T}$.

$G W P_{\Delta t} \simeq \frac{R F_{C O S}}{R F_{C O_{2}}} \times \frac{\tau_{C O S}}{\tau_{C O_{2}}} \times \frac{1-\exp \frac{-\Delta t}{\tau_{C O S}}}{1-\exp \frac{-\Delta t}{\tau_{C O_{2}}}}$

We assumed an overall lifetime of $\tau_{C O S}=3.8 \mathrm{yr}$ and $\tau_{\mathrm{CO}_{2}}=75 \mathrm{yr}$, and the radiative forcing of $1 \mathrm{~kg}$ of COS relative to $1 \mathrm{~kg}$ of $\mathrm{CO}_{2}$ added to the present atmosphere $\left(\mathrm{RF}_{C O S} / \mathrm{RF}_{\mathrm{CO}_{2}}\right)$ is 724 (Brühl and Crutzen, 1988). This results in a GWP of 111. For our time period, the mass of COS and $\mathrm{CO}_{2}$ added to the atmosphere $(\Delta m)$ is $1.9710^{12} \mathrm{~kg}$ of COS and $1.2310^{15} \mathrm{~kg}^{\circ} \mathrm{CO}_{2}$. Therefore, the COS radiative forcing can be calculated as:

$R F_{C O S}=G W P_{\Delta t} \times R F_{C O_{2}} \times \frac{\Delta m_{C O S}}{\Delta m_{C O_{2}}}$

where $\mathrm{RF}_{\mathrm{CO}_{2}}$ in RCP6.0 is estimated to be $0.83 \mathrm{~W} / \mathrm{m}^{2}$ considering an increase of $68.5 \mathrm{ppm}$ from a baseline of $409.2 \mathrm{ppm}$. Overall, this results in a radiative forcing from the COS increase of $0.17 \mathrm{~W} / \mathrm{m}^{2}$.

The main contributions of sulfate aerosols and clouds are summarised in tables S5 and S6 for SG-COS and SG-SO2, respectively. Globally, the estimated values are similar for the Clear-Sky SW and LW forcing from the sulfate aerosols: in terms of the latitudinal distribution, however, SG-SO2 presents a peak in the tropics whereas the forcing from SG-COS is much more latitudinally even.

The reduction in optical depth from cirrus clouds (see table 1) produced by the aerosols (Kuebbeler et al., 2012; Visioni et al., 2018a) results in a net negative radiative forcing given by the balance between the reduction of reflected solar radiation, resulting in a positive RF in the shortwave (SW) and the decrease of trapped planetary radiation, which reduces the contribution to the greenhouse effect with a negative RF in the longwave (LW). In the SG-COS case, at the equator the positive RF from the thinning locally cancels out the direct forcing from the aerosol (9 and fig. S6).

Table 6 summarises the total contribution of sulfate aerosols and greenhouse gases under All-Sky conditions.

\section{Technical feasibility of SG through COS emissions}

We briefly discuss here the technical feasibility of the approach described in this paper, as related to the increase of surface COS emissions (for $\mathrm{SO}_{2}$ injections, see for instance Smith and Wagner, 2018).

Patent number 3,409,399 (1968) has developed a method for high yield synthesis of COS (93.2-96.6\%): 


\section{All-Sky Radiative Forcing}

\section{(a) SG-COS}

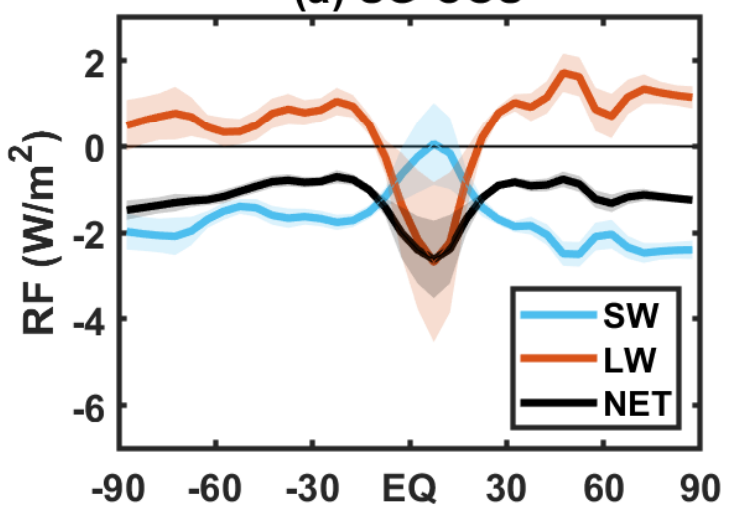

(b) SG-SO2

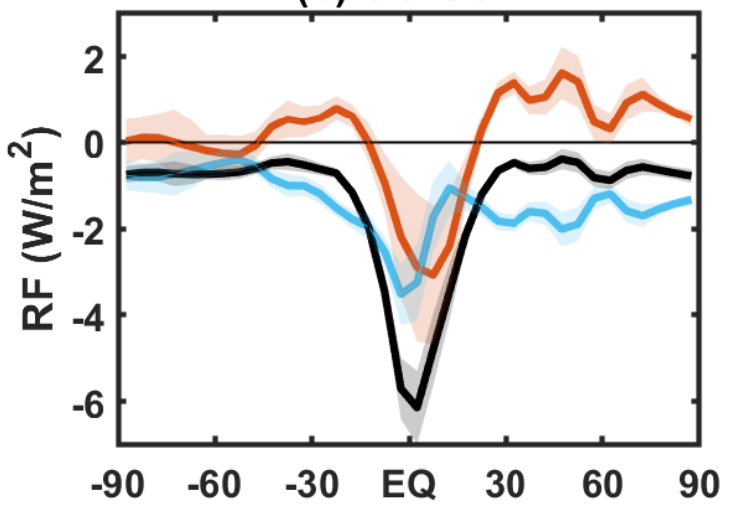

(c) Net

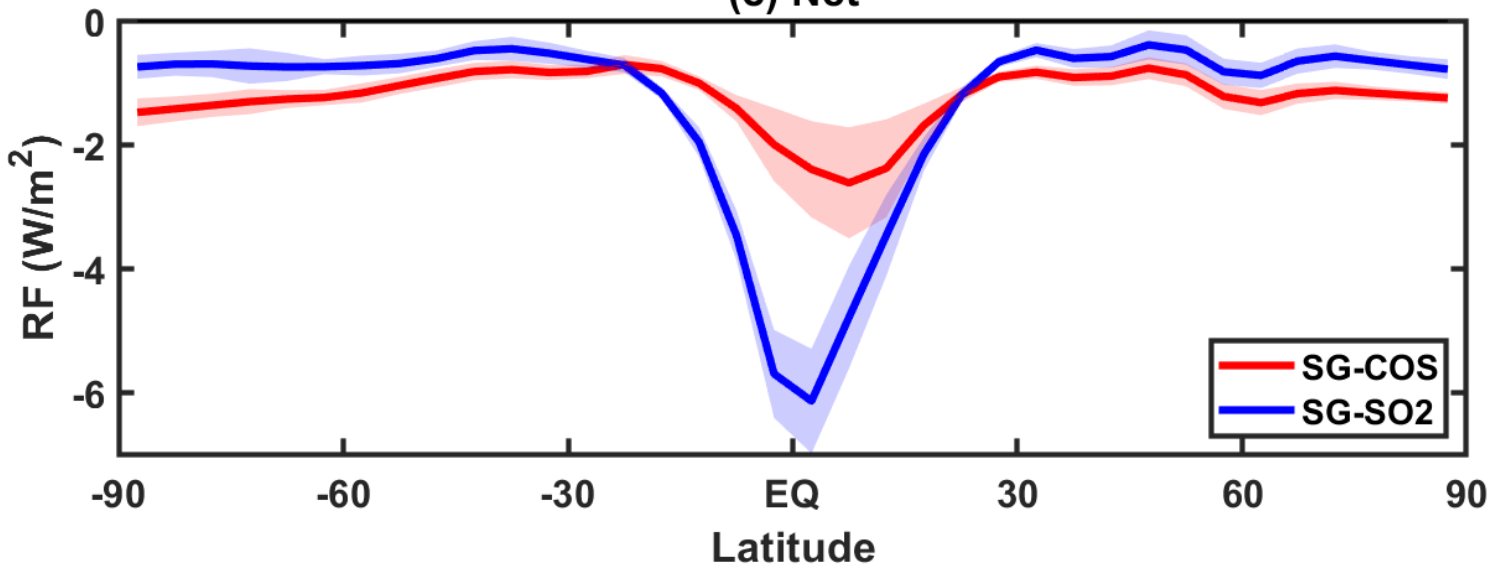

Figure 9. a-b) Mean zonal shortwave (cyan), longwave (orange), and net (black) radiative forcing (in W/m ${ }^{2}$ ) in SG-COS and SG-SO2 respectively. c) Comparison of the net radiative forcings from SG-COS (red) and SG-SO2 (blue). All quantities are annually averaged over the years 2046-2055. Shadings in all panels represent 1 standard deviation in the interannual variability. 
$\mathrm{CO}_{2}$ is abundant even in concentrated $(90 \%+)$ streams, from various natural and industrial sources, particularly with cooperation from states or industries. For example, capturing flue gas from coal-fired power plants is an established technology and may yield over $90 \% \mathrm{CO}_{2}$ (Wang et al., 2013). $\mathrm{CS}_{2}$ is produced via numerous means, perhaps the easiest being from coke (carbon) and molten sulfur:

$\mathrm{C}+2 \mathrm{~S} \stackrel{\text { high temperature }}{\longrightarrow} \mathrm{CS}_{2}$

Approximately 1 million tons of $\mathrm{CS}_{2}$ is produced per year (Madon and Strickland-Constable, 1958), with China consuming approximately half of the global production of $\mathrm{CS}_{2}$ for rayon manufacturing. $\mathrm{CS}_{2}$ is highly unstable and is flammable in air. It is also toxic at low concentrations (10 ppm).

Given the reactions above, about $0.5 \mathrm{Tg}$ of $\mathrm{S}$ will produce $0.94 \mathrm{Tg}$ of COS: this amounts to $0.16 \mathrm{Tg}$ of $\mathrm{C}$ (coke) and 0.55 $\mathrm{Tg}$ of molten sulfur. In the last decade, approximately $70 \mathrm{Tg}$ of sulfur were produced worldwide, so this would constitute an increase in S production of $0.8 \%$. The price varied between $\$ 50$ and $\$ 200$ per ton, leading to an annual cost of approximately \$25-100 million. Worldwide production of coke was around $640 \mathrm{Tg}$, so this increase in production is negligible. The price of coke varies between $\$ 50$ and $\$ 100$ per ton, leading to an annual cost of approximately $\$ 8$-16 million.

To this we would have to add the cost of $\mathrm{CO}_{2}$, as well as the production and energy costs. Considering an estimate of $\$ 400$ million per year for each $\mathrm{Tg}$ of $\mathrm{S}$ between $\mathrm{CO}_{2}$ and production and energy cost, and assuming an effort shared between 1000 locations, this would add up to $\$ 400.000$ per location per year per each $\mathrm{Tg}$ of $\mathrm{S}$. The overall cost is roughly of the same order of magnitude as that in Smith and Wagner (2018) for a stratospheric aerosol deployment at $\sim 20 \mathrm{~km}$ of injection (so different from the injection set-up in our study for SG-SO2), but without the need to develop a new aircraft-based delivery system.

\section{Conclusions}

We have presented here the results of a modeling experiment with the aim of producing an optically thick cloud of sulfate aerosols in the stratosphere without the injection of sulfate precursors directly in the stratosphere, but rather using increased surface emissions of carbonyl sulfide (COS). The low reactivity of COS in the troposphere, where it is not reactive and where it is predominantly absorbed by some soils and by plants, allows for a large portion of its emissions to reach the stratosphere, where it is turned into sulfate aerosols by photo-dissociation and oxidation.

We compare the results obtained with an increased emission of $40 \mathrm{Tg}-\mathrm{S} / \mathrm{yr}$ (roughly 400 times more than the background emissions) with those from a $4 \mathrm{Tg}-\mathrm{S} / \mathrm{yr}$ injection of $\mathrm{SO}_{2}$ in the stratosphere as prescribed in previous experiments (Kravitz 
et al., 2011; Visioni et al., 2017a). Both experiments result in a similar global optical depth from the produced stratospheric aerosols ( 0.07), but with different latitudinal distributions: for $\mathrm{SO}_{2}$, as previously observed in various modeling experiments, equatorial injections result in an increased concentration of aerosols in the tropical stratosphere that tends to overcool the tropics and undercool the high latitudes (Kravitz et al., 2018; Jiang et al., 2019), while also reducing the efficacy of the back-scattering from the aerosols due to the increased size of the particles (Visioni et al., 2018c). On the other hand, with COS emissions the uniform mixing of the gas allows for a more uniform distribution of the produced aerosols in the stratosphere, resulting in increased optical depth also at very high latitude.

The differences in distribution and size of the particles result in different changes to the composition of the atmosphere: smaller particles absorb and heat the stratosphere less, thus resulting in fewer dynamical changes. From a chemical perspective, stratospheric ozone would be impacted differently from the two geoengineering schemes. For $\mathrm{SO}_{2}$ injections, previous studies have shown that the overall effect is the result of a combination of various dynamical and chemical factors that behave differently depending on the latitude and altitude of the aerosols.

At low latitudes the increase in lower stratospheric water vapor produced by the warming of the tropopause layer enhances the halogen-driven destruction of ozone in the lower stratosphere (Tilmes et al., 2018b) due to $\mathrm{NO}_{x}$ depletion. This effect is balanced by reduced ozone destruction in the middle stratosphere due to the slowing down of the $\mathrm{NO}_{x}$ cycle produced by enhanced heterogeneous chemistry (Pitari et al., 2014; Richter et al., 2017; Franke et al., 2020).

Overall, in the case of COS emissions the further increase in SAD produced by smaller particles increases the inhibition of the ozone cycles in the middle stratosphere, resulting in a net increase in stratospheric ozone and thus in a larger decrease of UV radiation at the surface. Similarly, the larger sulfate burden at high latitudes produces further ozone recovery and thus less $\mathrm{UV}$ radiation also at the poles for the COS case.

Our results point to the feasibility of surface emissions of $\mathrm{COS}$ as a possible substitute to stratospheric $\mathrm{SO}_{2}$ (or other sulfate precursors) injections to produce stratospheric sulfate aerosols. This would sidestep the problem of deploying methods not already available to bring the sulfate at those altitudes, including development of novel aircraft (Bingaman et al., 2020).

Since COS is already a byproduct of human activities, it might be possible to devise methods of mass-production of the required quantities that may be cheaper than the known proposed methods (Smith et al., 2020).

Overall, there are some weak points in a geoengineering strategy using COS compared to $\mathrm{SO}_{2}$ that need to be addressed. First, it necessitates a larger amount of emissions to achieve the same global stratospheric AOD, resulting in larger amounts of deposition. It would be less easily scalable, and both deployment and phase-out, as we have shown, would require a much longer time-frame compared to the almost instantaneous effect produced by $\mathrm{SO}_{2}$ injections. Considering the dangers to ecosystems presented by a too fast deployment or termination of sulfate geoengineering (Trisos et al., 2018), this might not actually be a large drawback, but it does remove the possibility of rapidly "regulating" the necessary amount of stratospheric sulfate in case of changes in strategy or external conditions (such as a Pinatubo-like volcanic eruption; Laakso et al., 2016). Furthermore, the mixing happening in the troposphere would not allow any control in the latitudinal or seasonal distribution of the resulting aerosols, as proposed elsewhere (MacMartin et al., 2017; Dai et al., 2018; Visioni et al., 2019). 
Clearly, this study is intended to be just a pilot study of this newly proposed method, and further simulations with other climate models, possibly with a coupled ocean and interactive land model, to determine the surface response, are needed. The agreement between the baseline results presented here and the information present in the literature point to a robustness of our results, but further studies are required to understand different aspects of the climate response: for instance, studies would need to investigate the possible response of vegetation and soils to the increased concentration of COS in the troposphere, and if the efficacy of the sinks would change due to shifts in temperature and precipitation produced by both climate change and the intervention.

365 While toxic levels of COS concentrations are many orders of magnitude larger than the one achieved in our simulations (Kilburn and Warshaw, 1995; Bartholomaeus and Haritos, 2006), the effects of prolonged exposure to lower concentrations will have to be assessed. Estimations of the tropospheric radiative effect would also need to be refined to make sure that it is not larger than previously estimated, reducing the efficacy of the aerosol-induced cooling. Overall, however, the results obtained in this work show that, as a geoengineering technique, the surface emission of carbonyl sulfide should be further studied and considered by the scientific community as a possible alternative to the others already studied in the literature.

Data availability. Data used in this work will be made available through the Cornell eCommons platform before publication.

Author contributions. DV and GP devised the study. IQ ran the simulations, analysed the results, produced the figures and wrote the manuscript with the assistance of DV. BK wrote Section 6 and contributed to the final draft of the manuscript.

Competing interests. The authors declare no competing interests D.V. was provided by the Atkinson Center for a Sustainable Future at Cornell University. 


\section{References}

Barkley, M. P., Palmer, P. I., Boone, C. D., Bernath, P. F., and Suntharalingam, P.: Global distributions of carbonyl sulfide in the upper troposphere and stratosphere, Geophysical Research Letters, 35, https://doi.org/https://doi.org/10.1029/2008GL034270, 2008.

Bartholomaeus, A. and Haritos, V.: Review of the toxicology of carbonyl sulfide, a new grain fumigant, Food and chemical toxicology : an international journal published for the British Industrial Biological Research Association, 43, 1687-701, https://doi.org/10.1016/j.fct.2005.06.016, 2006.

Bingaman, D. C., Rice, C. V., Smith, W., and Vogel, P.: A Stratospheric Aerosol Injection Lofter Aircraft Concept: Brimstone Angel, in: AIAA Scitech 2020 Forum, AIAA SciTech Forum, American Institute of Aeronautics and Astronautics, https://doi.org/10.2514/6.20200618, 2020.

Bruhl, C., Lelieveld, J., Crutzen, P. J., and Tost, H.: The role of carbonyl sulphide as a source of stratospheric sulphate aerosol and its impact on climate, Atmospheric Chemistry and Physics, 12, 1239-1253, 2012.

Brühl, C. and Crutzen, P. J.: Scenarios of possible changes in atmospheric temperatures and ozone concentrations due to man's activities, estimated with a one-dimensional coupled photochemical climate model, Climate Dynamics, 2, 173-203, https://doi.org/10.1007/BF01053474, 1988.

Budyko, M. I.: The Climate of the Future, American Geophysical Union, https://doi.org/10.1002/9781118665251.ch7, 1978.

Crutzen, P. J.: The possible importance of CSO for the sulfate layer of the stratosphere, Geophysical Research Letters, 3, 73-76, https://doi.org/https://doi.org/10.1029/GL003i002p00073, 1976.

Crutzen, P. J.: Albedo Enhancement by Stratospheric Sulfur Injections: A Contribution to Resolve a Policy Dilemma?, Climatic Change, 77, 211-220, https://doi.org/10.1007/s10584-006-9101-y, 2006.

Dai, Z., Weisenstein, D. K., and Keith, D. W.: Tailoring Meridional and Seasonal Radiative Forcing by Sulfate Aerosol Solar Geoengineering, Geophysical Research Letters, 45, 1030-1039, https://doi.org/10.1002/2017GL076472, 2018.

Driscoll, C. T., Lawrence, G. B., Bulger, A. J., Butler, T. J., Cronan, C. S., Eagar, C., Lambert, K. F., Likens, G. E., Stoddard, J. L., and Weathers, K. C.: Acidic Deposition in the Northeastern United States: Sources and Inputs, Ecosystem Effects, and Management Strategies: The effects of acidic deposition in the northeastern United States include the acidification of soil and water, which stresses terrestrial and aquatic biota, BioScience, 51, 180-198, https://doi.org/10.1641/0006-3568(2001)051[0180:ADITNU]2.0.CO;2, 2001.

Eastham, S. D., Weisenstein, D. K., Keith, D. W., and Barrett, S. R.: Quantifying the impact of sulfate geoengineering on mortality from air quality and UV-B exposure, Atmospheric Environment, 187, 424 - 434, https://doi.org/https://doi.org/10.1016/j.atmosenv.2018.05.047, 2018.

Eichinger, R., Dietmuller, S., Garny, H., Sacha, P., Birner, T., Bonisch, H., Pitari, G., Visioni, D., Stenke, A., Rozanov, E., Revell, L., Plummer, D. A., Jockel, P., Oman, L., Deushi, M., Kinnison, D. E., Garcia, R., Morgenstern, O., Zeng, G., Stone, K. A., and Schofield, R.: The influence of mixing on the stratospheric age of air changes in the 21st century, Atmospheric Chemistry and Physics, 19, 921-940, 2019.

410 English, J. M., Toon, O. B., and Mills, M. J.: Microphysical simulations of sulfur burdens from stratospheric sulfur geoengineering, Atmospheric Chemistry and Physics, 12, 4775-4793, 2012.

Eyring, V., Butchart, N., Waugh, D. W., Akiyoshi, H., Austin, J., Bekki, S., Bodeker, G. E., Boville, B. A., Brühl, C., Chipperfield, M. P., Cordero, E., Dameris, M., Deushi, M., Fioletov, V. E., Frith, S. M., Garcia, R. R., Gettelman, A., Giorgetta, M. A., Grewe, V., Jourdain, L., Kinnison, D. E., Mancini, E., Manzini, E., Marchand, M., Marsh, D. R., Nagashima, T., Newman, P. A., Nielsen, J. E., Pawson, S., Pitari, 

Assessment of temperature, trace species, and ozone in chemistry-climate model simulations of the recent past, Journal of Geophysical Research, 111, D22 308, https://doi.org/10.1029/2006JD007327, 2006.

Franke, H., Niemeier, U., and Visioni, D.: Differences in the QBO response to stratospheric aerosol modification depending on injection strategy and species, Atmospheric Chemistry and Physics Discussions, 2020, 1-29, https://doi.org/10.5194/acp-2020-1104, 2020.

Grant, W., Fishman, J., Browell, E., Brackett, V., Nganga, D., Minga, A., Cros, B., Veiga, R. E., Butler, C., Fenn, M., and Nowicki, G.: Observations of reduced ozone concentrations in the tropical stratosphere after the eruption of Mt. Pinatubo, Geophysical Research Letters, 19, 1109-1112, 1992.

Jiang, J., Cao, L., MacMartin, D. G., Simpson, I. R., Kravitz, B., Cheng, W., Visioni, D., Tilmes, S., Richter, J. H., and Mills, M. J.: Stratospheric Sulfate Aerosol Geoengineering Could Alter the High-Latitude Seasonal Cycle, Geophysical Research Letters, 46, 14 15314 163, https://doi.org/10.1029/2019GL085758, 2019.

Kettle, A. J., Kuhn, U., von Hobe, M., Kesselmeier, J., and Andreae, M. O.: Global budget of atmospheric carbonyl sulfide: Temporal and spatial variations of the dominant sources and sinks, Journal of Geophysical Research: Atmospheres, 107, ACH 25-1-ACH 25-16, https://doi.org/https://doi.org/10.1029/2002JD002187, 2002.

Khalil, M. and Rasmussen, R.: Global sources, lifetimes and mass balances of carbonyl sulfide (OCS) and carbon disulfide (CS2) in the earth's atmosphere, Atmospheric Environment (1967), 18, 1805-1813, 1984.

Kilburn, K. H. and Warshaw, R. H.: Hydrogen Sulfide and Reduced-Sulfur Gases Adversely Affect Neurophysiological Functions, Toxicology and Industrial Health, 11, 185-197, 1995.

Kravitz, B., Robock, A., Boucher, O., Schmidt, H., Taylor, K. E., Stenchikov, G., and Schulz, M.: The Geoengineering Model Intercomparison Project (GeoMIP), Atmospheric Science Letters, 12, 162-167, https://doi.org/10.1002/asl.316, 2011.

Kravitz, B., Rasch, P. J., Wang, H., Robock, A., Gabriel, C., Boucher, O., Cole, J. N. S., Haywood, J., Ji, D., Jones, A., Lenton, A., Moore, J. C., Muri, H., Niemeier, U., Phipps, S., Schmidt, H., Watanabe, S., Yang, S., and Yoon, J.-H.: The climate effects of increasing ocean albedo: an idealized representation of solar geoengineering, Atmospheric Chemistry and Physics, 18, 13 097-13 113, https://doi.org/10.5194/acp-18-13097-2018, 2018.

Kuai, L., Worden, J. R., Campbell, J. E., Kulawik, S. S., Li, K.-F., Lee, M., Weidner, R. J., Montzka, S. A., Moore, F. L., Berry, J. A., Baker, I., Denning, A. S., Bian, H., Bowman, K. W., Liu, J., and Yung, Y. L.: Estimate of carbonyl sulfide tropical oceanic surface fluxes using Aura Tropospheric Emission Spectrometer observations, Journal of Geophysical Research: Atmospheres, 120, 11,012-11,023, https://doi.org/https://doi.org/10.1002/2015JD023493, 2015.

Kuebbeler, M., Lohmann, U., and Feichter, J.: Effects of stratospheric sulfate aerosol geo-engineering on cirrus clouds, Geophysical Research Letters, 39, https://doi.org/10.1029/2012GL053797, 123803, 2012.

445 Kuhn, U. and Kesselmeier, J.: Environmental variables controlling the uptake of carbonyl sulfide by lichens, Journal of Geophysical Research: Atmospheres, 105, 26 783-26 792, https://doi.org/https://doi.org/10.1029/2000JD900436, 2000.

Laakso, A., Kokkola, H., Partanen, A.-I., Niemeier, U., Timmreck, C., Lehtinen, K. E. J., Hakkarainen, H., and Korhonen, H.: Radiative and climate impacts of a large volcanic eruption during stratospheric sulfur geoengineering, Atmospheric Chemistry and Physics, 16, 305-323, https://doi.org/10.5194/acp-16-305-2016, 2016.

450 Labitzke, K. and McCormick, M. P.: Stratospheric temperature increases due to Pinatubo aerosols, Geophysical Research Letters, 19, 207210, https://doi.org/10.1029/91GL02940, 1992. 
Lacis, A., Hansen, J., and Sato, M.: Climate forcing by stratospheric aerosols, Geophysical Research Letters, 19, 1607-1610, https://doi.org/https://doi.org/10.1029/92GL01620, 1992.

Lamarque, J.-F., Dentener, F., McConnell, J., Ro, C.-U., Shaw, M., Vet, R., Bergmann, D., Cameron-Smith, P., Dalsoren, S., Doherty, R.,

Faluvegi, G., Ghan, S. J., Josse, B., Lee, Y. H., MacKenzie, I. A., Plummer, D., Shindell, D. T., Skeie, R. B., Stevenson, D. S., Strode, S., Zeng, G., Curran, M., Dahl-Jensen, D., Das, S., Fritzsche, D., and Nolan, M.: Multi-model mean nitrogen and sulfur deposition from the Atmospheric Chemistry and Climate Model Intercomparison Project (ACCMIP): evaluation of historical and projected future changes, Atmospheric Chemistry and Physics, 13, 7997-8018, https://doi.org/10.5194/acp-13-7997-2013, 2013.

Lee, C.-L. and Brimblecombe, P.: Anthropogenic contributions to global carbonyl sulfide, carbon disulfide and organosulfides fluxes, EarthScience Reviews, 160, 1-18, https://doi.org/https://doi.org/10.1016/j.earscirev.2016.06.005, 2016.

Lockley, A., MacMartin, D., and Hunt, H.: An update on engineering issues concerning stratospheric aerosol injection for geoengineering, Environmental Research Communications, 2, 082 001, 2020.

MacMartin, D. G., Kravitz, B., Mills, M. J., Tribbia, J. J., Tilmes, S., Richter, J. H., Vitt, F., and Lamarque, J.-F.: The Climate Response to Stratospheric Aerosol Geoengineering Can Be Tailored Using Multiple Injection Locations, Journal of Geophysical Research: Atmospheres, 122, 12,574-12,590, https://doi.org/10.1002/2017jd026868, 2017.

Madon, H. N. and Strickland-Constable, R. F.: Production of CS2, Industrial \& Engineering Chemistry, 50, 1189-1192, 1958.

Madronich, S., Tilmes, S., Kravitz, B., MacMartin, D. G., and Richter, J. H.: Response of surface ultraviolet and visible radiation to stratospheric SO2 injections, Atmosphere, 9, https://doi.org/10.3390/atmos9110432, 2018.

Meinshausen, M., Smith, S. J., Calvin, K., Daniel, J. S., Kainuma, M. L. T., Lamarque, J.-F., Matsumoto, K., Montzka, S. A., Raper, S. C. B.,

Riahi, K., Thomson, A., Velders, G. J. M., and van Vuuren, D. P. P.: The RCP greenhouse gas concentrations and their extensions from 1765 to 2300, Climatic Change, 109, 213, 2011.

Morgenstern, O., Giorgetta, M. A., Shibata, K., Eyring, V., Waugh, D. W., Shepherd, T. G., Akiyoshi, H., Austin, J., Baumgaertner, A. J. G., Bekki, S., Braesicke, P., Brühl, C., Chipperfield, M. P., Cugnet, D., Dameris, M., Dhomse, S., Frith, S. M., Garny, H., Gettelman, A., Hardiman, S. C., Hegglin, M. I., Jöckel, P., Kinnison, D. E., Lamarque, J.-F., Mancini, E., Manzini, E., Marchand, M., Michou, M., Nakamura, T., Nielsen, J. E., Olivié, D., Pitari, G., Plummer, D. A., Rozanov, E., Scinocca, J. F., Smale, D., Teyssèdre, H., Toohey, M., Tian, W., and Yamashita, Y.: Review of the formulation of present-generation stratospheric chemistry-climate models and associated external forcings, Journal of Geophysical Research, 115, D00M02, https://doi.org/10.1029/2009JD013728, 2010.

Morgenstern, O., Stone, K. A., Schofield, R., Akiyoshi, H., Yamashita, Y., Kinnison, D. E., Garcia, R. R., Sudo, K., Plummer, D. A., Scinocca, J., Oman, L. D., Manyin, M. E., Zeng, G., Rozanov, E., Stenke, A., Revell, L. E., Pitari, G., Mancini, E., Di Genova, G., Visioni, D., Dhomse, S. S., and Chipperfield, M. P.: Ozone sensitivity to varying greenhouse gases and ozone-depleting substances in CCMI-1 simulations, Atmospheric Chemistry and Physics, 18, 1091-1114, https://doi.org/10.5194/acp-18-1091-2018, 2018.

Mu, Y., Geng, C., Wang, M., Wu, H., Zhang, X., and Jiang, G.: Photochemical production of carbonyl sulfide in precipitation, Journal of Geophysical Research: Atmospheres, 109, https://doi.org/https://doi.org/10.1029/2003JD004206, 2004.

Neale, R. B., Richter, J., Park, S., Lauritzen, P. H., Vavrus, S. J., Rasch, P. J., and Zhang, M.: The Mean Climate of the Community Atmosphere Model (CAM4) in Forced SST and Fully Coupled Experiments, Journal of Climate, 26, 5150 - 5168, 2013.

Nowack, P. J., Abraham, N. L., Braesicke, P., and Pyle, J. A.: Stratospheric ozone changes under solar geoengineering: implications for UV exposure and air quality, Atmospheric Chemistry and Physics, 16, 4191-4203, https://doi.org/10.5194/acp-16-4191-2016, 2016.

Orbe, C., Yang, H., Waugh, D. W., Zeng, G., Morgenstern, O., Kinnison, D. E., Lamarque, J.-F., Tilmes, S., Plummer, D. A., Scinocca, J. F., Josse, B., Marecal, V., Jöckel, P., Oman, L. D., Strahan, S. E., Deushi, M., Tanaka, T. Y., Yoshida, K., Akiyoshi, H., Yamashita, Y., Stenke, 

transport in the Chemistry-Climate Model Initiative (CCMI) simulations, Atmospheric Chemistry and Physics, 18, 7217-7235, 2018.

Pitari, G., Mancini, E., Rizi, V., and Shindell, D. T.: Impact of Future Climate and Emission Changes on Stratospheric Aerosols and Ozone, Journal of the Atmospheric Sciences, 59, 414-440, https://doi.org/10.1175/1520-0469(2002)059<0414:IOFCAE>2.0.CO;2, place: Boston MA, USA Publisher: American Meteorological Society, 2002.

Pitari, G., Aquila, V., Kravitz, B., Robock, A., Watanabe, S., Cionni, I., Luca, N. D., Genova, G. D., Mancini, E., and Tilmes, S.: Stratospheric ozone response to sulfate geoengineering: Results from the Geoengineering Model Intercomparison Project (GeoMIP), Journal of Geophysical Research: Atmospheres, 119, 2629-2653, https://doi.org/10.1002/2013JD020566, 2014.

Richter, J. H., Tilmes, S., Mills, M. J., Tribbia, J. J., Kravitz, B., Macmartin, D. G., Vitt, F., and Lamarque, J. F.: Stratospheric dynamical response and ozone feedbacks in the presence of SO2 injections, Journal of Geophysical Research: Atmospheres, 122, 12,557-12,573, https://doi.org/10.1002/2017JD026912, 2017.

Robock, A.: Volcanic eruptions and climate, Reviews of Geophysics, 38, 191-219, https://doi.org/10.1029/1998RG000054, 2000.

Roehl, C. M., Boglu, D., Brühl, C., and Moortgat, G. K.: Infrared band intensities and global warming potentials of CF4, C2F6, C3F8, C4F10, C5F12, and C6F14, Geophysical Research Letters, 22, 815-818, https://doi.org/https://doi.org/10.1029/95GL00488, 1995.

Sandoval-Soto, L., Stanimirov, M., von Hobe, M., Schmitt, V., Valdes, J., Wild, A., and Kesselmeier, J.: Global uptake of carbonyl sulfide (COS) by terrestrial vegetation: Estimates corrected by deposition velocities normalized to the uptake of carbon dioxide $\left(\mathrm{CO}_{2}\right)$, $\mathrm{Biogeo-}$ sciences, 2, 125-132, https://doi.org/10.5194/bg-2-125-2005, 2005.

Smith, C. J., Kramer, R. J., Myhre, G., Alterskjær, K., Collins, W., Sima, A., Boucher, O., Dufresne, J.-L., Nabat, P., Michou, M., Yukimoto, S., Cole, J., Paynter, D., Shiogama, H., O’Connor, F. M., Robertson, E., Wiltshire, A., Andrews, T., Hannay, C., Miller, R., Nazarenko, L., Kirkevlaag, A., Olivié, D., Fiedler, S., Lewinschal, A., Mackallah, C., Dix, M., Pincus, R., and Forster, P. M.: Effective radiative forcing and adjustments in CMIP6 models, Atmospheric Chemistry and Physics, 20, 9591-9618, https://doi.org/10.5194/acp-20-9591-2020, 2020.

Smith, W. and Wagner, G.: Stratospheric aerosol injection tactics and costs in the first 15 years of deployment, Environmental Research Letters, 13, 124 001, https://doi.org/10.1088/1748-9326/aae98d, 2018.

Steinbacher, M., Bingemer, H. G., and Schmidt, U.: Measurements of the exchange of carbonyl sulfide (OCS) and carbon disulfide (CS2) between soil and atmosphere in a spruce forest in central Germany, Atmospheric Environment, 38, 6043-6052, https://doi.org/https://doi.org/10.1016/j.atmosenv.2004.06.022, 2004.

Tilmes, S., Müller, R., and Salawitch, R.: The Sensitivity of Polar Ozone Depletion to Proposed Geoengineering Schemes, Science, 320, 1201-1204, https://doi.org/10.1126/science.1153966, 2008.

Tilmes, S., Garcia, R. R., Kinnison, D. E., Gettelman, A., and Rasch, P. J.: Impact of geoengineered aerosols on the troposphere and stratosphere, Journal of Geophysical Research: Atmospheres, 114, https://doi.org/https://doi.org/10.1029/2008JD011420, 2009.

Tilmes, S., Mills, M. J., Niemeier, U., Schmidt, H., Robock, A., Kravitz, B., Lamarque, J.-F., Pitari, G., and English, J. M.: A new Geoengineering Model Intercomparison Project (GeoMIP) experiment designed for climate and chemistry models, Geoscientific Model Development, 8, 43-49, https://doi.org/10.5194/gmd-8-43-2015, 2015.

Tilmes, S., Richter, J. H., Kravitz, B., Macmartin, D. G., Mills, M. J., Simpson, I. R., Glanville, A. S., Fasullo, J. T., Phillips, A. S., Lamarque, J. F., Tribbia, J., Edwards, J., Mickelson, S., and Ghosh, S.: CESM1(WACCM) stratospheric aerosol geoengineering large ensemble project, Bulletin of the American Meteorological Society, pp. 2361-2371, https://doi.org/10.1175/BAMS-D-17-0267.1, 2018a. 
Tilmes, S., Richter, J. H., Mills, M. J., Kravitz, B., MacMartin, D. G., Garcia, R. R., Kinnison, D. E., Lamarque, J. F., Tribbia, J., and Vitt, F.: Effects of Different Stratospheric SO2 Injection Altitudes on Stratospheric Chemistry and Dynamics, Journal of Geophysical Research: Atmospheres, 123, 4654-4673, https://doi.org/10.1002/2017JD028146, 2018b.

Tilmes, S., Richter, J. H., MacMartin, D. G., Kravitz, B., Glanville, A., Visioni, D., , Kinnison, D., and Mueller, R.: Sensitivity of total column ozone to stratospheric sulfur injection strategies, Geophysical Research Letters, n/a, n/a, inreview, 2021.

Trisos, C. H., Amatulli, G., Gurevitch, J., Robock, A., Xia, L., and Zambri, B.: Potentially dangerous consequences for biodiversity of solar geoengineering implementation and termination, Nature Ecology \& Evolution, 2, 475-482, https://doi.org/10.1038/s41559-017-0431-0, 2018.

Ulshofer, V., Flock, O., Uher, G., and Andreae, M.: Photochemical production and air-sea exchange of carbonyl sulfide in the eastern Mediterranean Sea, Marine Chemistry, 53, 25-39, 1996.

Van Diest, H. and Kesselmeier, J.: Soil atmosphere exchange of carbonyl sulfide (COS) regulated by diffusivity depending on water-filled pore space, Biogeosciences, 5, 475-483, https://doi.org/10.5194/bg-5-475-2008, 2008.

Vattioni, S., Weisenstein, D., Keith, D., Feinberg, A., Peter, T., and Stenke, A.: Exploring accumulation-mode H2SO4 versus SO2 stratospheric sulfate geoengineering in a sectional aerosol-chemistry-climate model, Atmospheric Chemistry and Physics, 19, 4877-4897, https://doi.org/10.5194/acp-19-4877-2019, 2019.

Visioni, D., Pitari, G., Aquila, V., Tilmes, S., Cionni, I., Di Genova, G., and Mancini, E.: Sulfate geoengineering impact on methane transport and lifetime: results from the Geoengineering Model Intercomparison Project (GeoMIP), Atmospheric Chemistry and Physics, 17, 11 20911 226, https://doi.org/10.5194/acp-17-11209-2017, 2017a.

Visioni, D., Pitari, G., Aquila, V., Tilmes, S., Cionni, I., Di Genova, G., and Mancini, E.: Sulfate geoengineering impact on methane transport and lifetime: results from the Geoengineering Model Intercomparison Project (GeoMIP), Atmospheric Chemistry and Physics, 17, 11 209_ 11 226, https://doi.org/10.5194/acp-17-11209-2017, 2017b.

Visioni, D., Pitari, G., Di Genova, G., Tilmes, S., and Cionni, I.: Upper tropospheric ice sensitivity to sulfate geoengineering, Atmospheric Chemistry and Physics, https://doi.org/10.5194/acp-18-14867-2018, 2018a.

Visioni, D., Pitari, G., Tuccella, P., and Curci, G.: Sulfur deposition changes under sulfate geoengineering conditions: Quasi-biennial oscillation effects on the transport and lifetime of stratospheric aerosols, Atmospheric Chemistry and Physics, https://doi.org/10.5194/acp-182787-2018, 2018b.

Visioni, D., Pitari, G., Tuccella, P., and Curci, G.: Sulfur deposition changes under sulfate geoengineering conditions: quasi-biennial oscillation effects on the transport and lifetime of stratospheric aerosols, Atmospheric Chemistry and Physics, 18, 2787-2808, https://doi.org/10.5194/acp-18-2787-2018, 2018c.

Visioni, D., MacMartin, D. G., Kravitz, B., Tilmes, S., Mills, M. J., Richter, J. H., and Boudreau, M. P.: Seasonal Injection Strategies for Stratospheric Aerosol Geoengineering, Geophysical Research Letters, 46, 7790-7799, https://doi.org/10.1029/2019GL083680, 2019.

Visioni, D., MacMartin, D. G., Kravitz, B., Lee, W., Simpson, I. R., and Richter, J. H.: Reduced Poleward Transport Due to Stratospheric Heating Under Stratospheric Aerosols Geoengineering, Geophysical Research Letters, 47, e2020GL089470, https://doi.org/https://doi.org/10.1029/2020GL089470, e2020GL089470 10.1029/2020GL089470, 2020.

560 Visioni, D., MacMartin, D. G., and Kravitz, B.: Is Turning Down the Sun a Good Proxy for Stratospheric Sulfate Geoengineering?, Journal of Geophysical Research: Atmospheres, 126, e2020JD033 952, https://doi.org/https://doi.org/10.1029/2020JD033952, e2020JD033952 2020JD033952, 2021. 
https://doi.org/10.5194/acp-2021-813

Preprint. Discussion started: 11 October 2021

(C) Author(s) 2021. CC BY 4.0 License.

(c) (i)

Wang, L., Yang, Y., Shen, W., Kong, X., Li, P., Yu, J., and Rodrigues, A. E.: CO2 Capture from Flue Gas in an Existing Coal-Fired Power Plant by Two Successive Pilot-Scale VPSA Units, Industrial \& Engineering Chemistry Research, 52, 7947-7955, 2013.

565 West, J. J. and Fiore, A. M.: Management of Tropospheric Ozone by Reducing Methane Emissions, Environmental Science \& Technology, 39, 4685-4691, https://doi.org/10.1021/es048629f, pMID: 16053064, 2005.

Whelan, M. E., Hilton, T. W., Berry, J. A., Berkelhammer, M., Desai, A. R., and Campbell, J. E.: Carbonyl sulfide exchange in soils for better estimates of ecosystem carbon uptake, Atmospheric Chemistry and Physics, 16, 3711-3726, 2016.

Xia, L., Nowack, P. J., Tilmes, S., and Robock, A.: Impacts of stratospheric sulfate geoengineering on tropospheric ozone, Atmospheric Chemistry and Physics, 17, 11913-11 928, https://doi.org/10.5194/acp-17-11913-2017, 2017a.

Xia, L., Nowack, P. J., Tilmes, S., and Robock, A.: Impacts of stratospheric sulfate geoengineering on tropospheric ozone, Atmospheric Chemistry and Physics, 17, 11 913-11 928, https://doi.org/10.5194/acp-17-11913-2017, 2017b. 